\title{
التنوع والسلم الأهلى فى الأطر الديمقراطية / الشبكات والمؤسسات

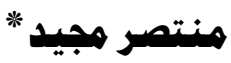

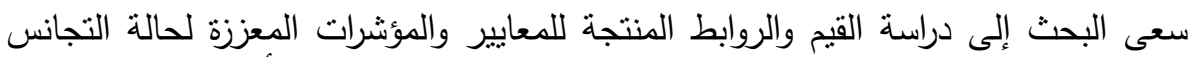

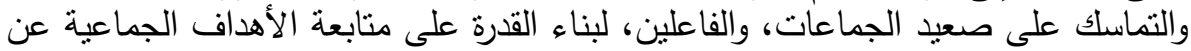

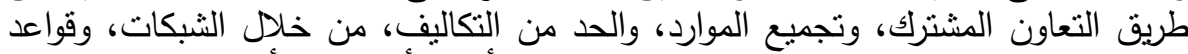

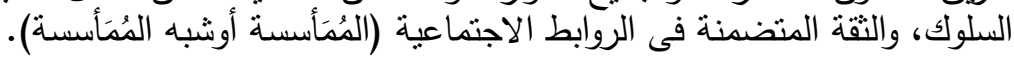

\section{مقدهة}

يواجه عالم اليوم مسارًا متصاعدًا نحو التعددية والتتوع، حيث بلغ عدد سكان

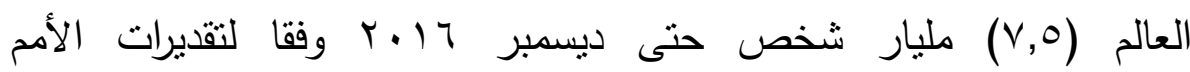
المتحدة(')، تتنمى هذه المليارات من البشر إلى حوالى ستة آلاف جماعة إثنية-

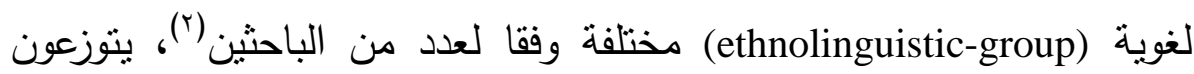

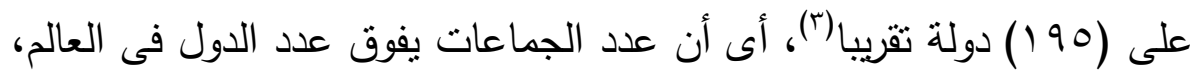

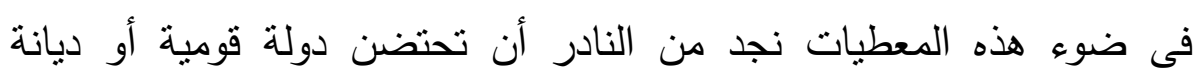
واحدة، إذ تتألف الدول من شعوب تتنمى لأعراق وجماعات وديانات متتوعة،

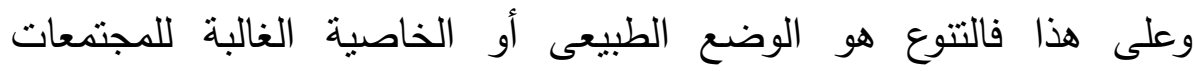

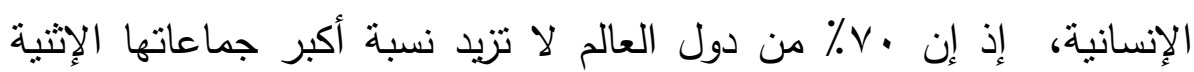

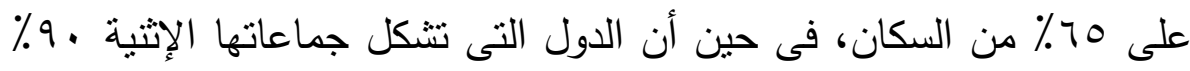

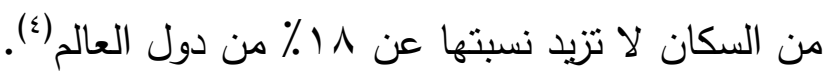
* أستاذ مساعد النظم السياسية، كلية العلوم السياسية، جامعة بغداد. المجلة الجنائية القومية، المجلد الواحد وإلستون، العدد الثانس، يوليو 1 ـ ـ ـ . 
ورغم أن التتوع ظاهرة طبيعية، إلا أن ظاهرة عدم التجانس أو التتوع

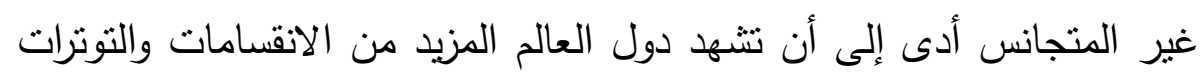

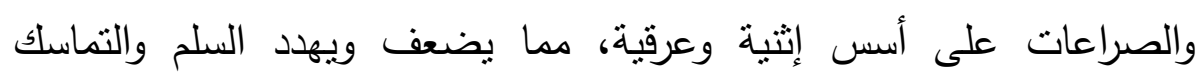

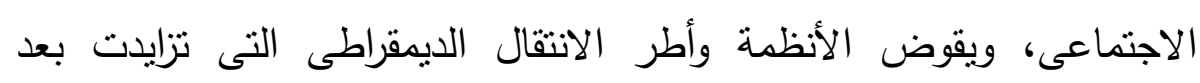

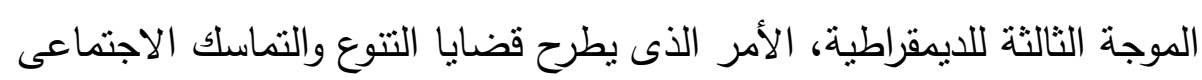
والسلم الأهلى على صعيدى السياسات والحياة المدنية للاول.

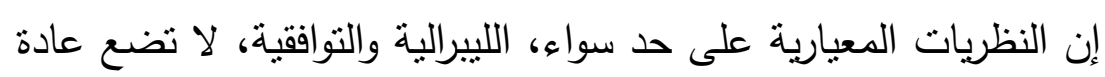

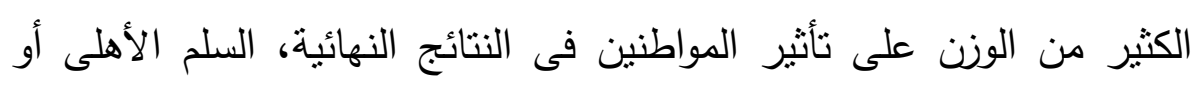

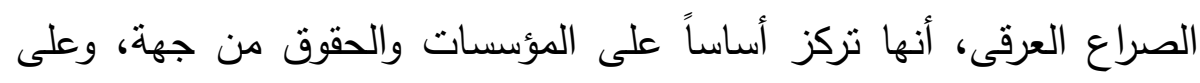

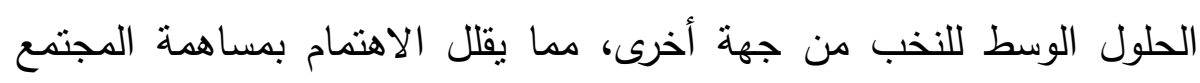

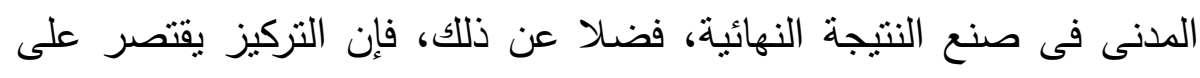
تأثير المؤسسات السياسية على استقرار الديمقراطية بمعنى غياب العنف، أى ألى العيان

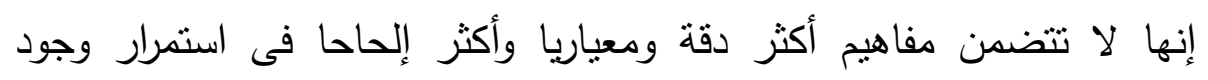
المجتمع السياسى (o).

إن التتوع الاجتماعى" بمغنى ما قد لا ينحدى فقط وجود الإحساس

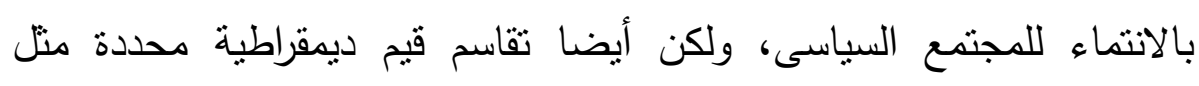

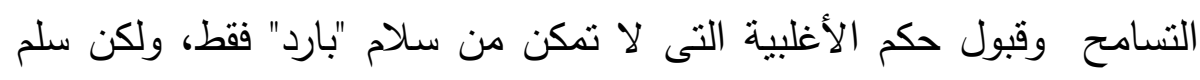
أهلى أكثر استقرارًا، ذلك أن غياب العنف هو أساس ألى ألى سلام مجتمعى، إلا أنه

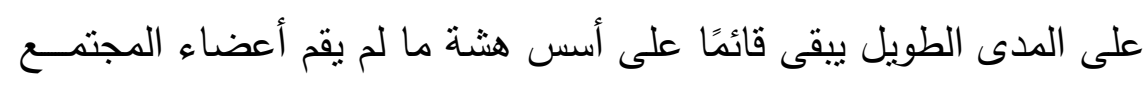

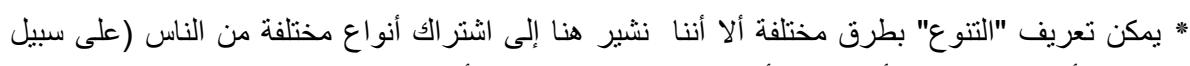
المثال، أناس من جنس ، أو عرق ، أو ثقافة مختلفة) فى جماعة أو رابطة اجتماعية. 
السياسى بنطوير مواقف وسلوكيات معـينة مثـل الرغبـة بالتـعاون

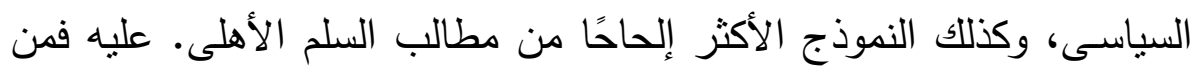

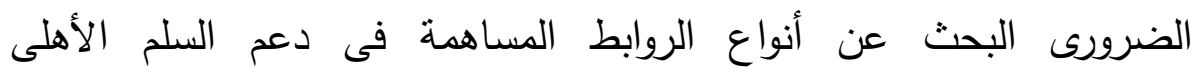

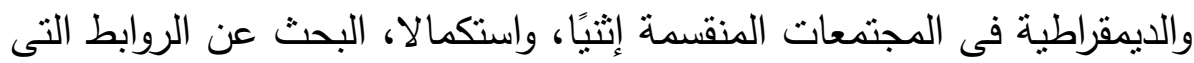

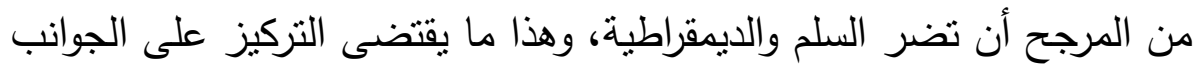

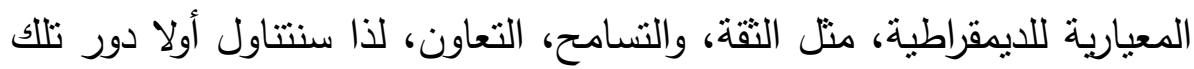

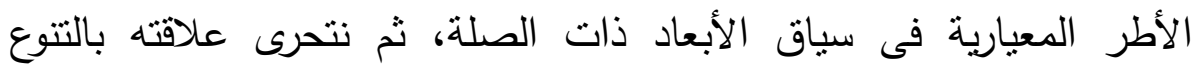
والانقسامات الإثتية فى إطار النظم الديمقراطية وعملية الانتقال أو الدمقرطة، وإنعكاسات ذللك على التتوع والسلم الأهلى.

\section{أولا: القيم والروابط المنتجة للديمقراطية والسلم الأهلى

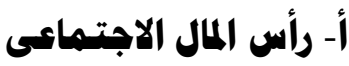

يعد رأس المال الاجتماعى بمثابة مقياس للتماسك الاجتماعى، وأحد مؤشرات

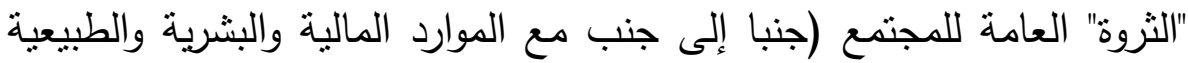

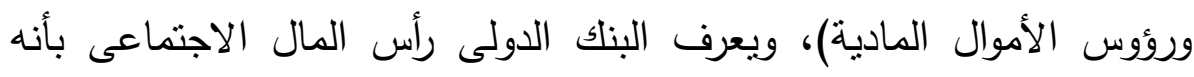

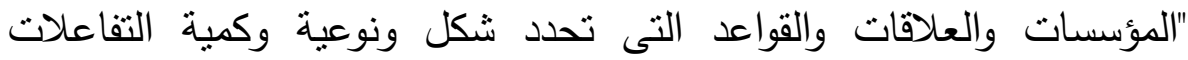

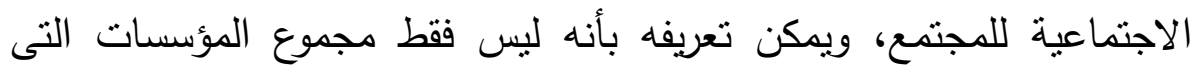

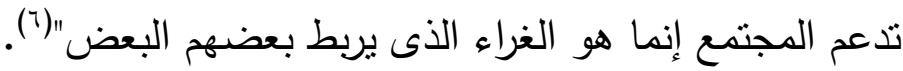

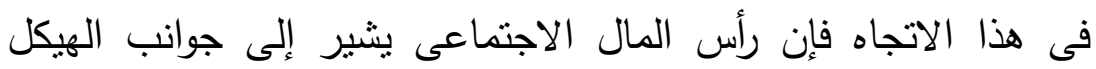

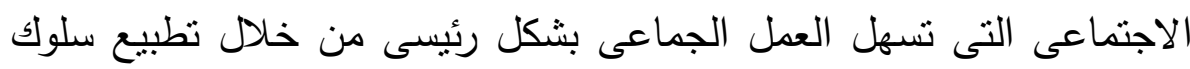

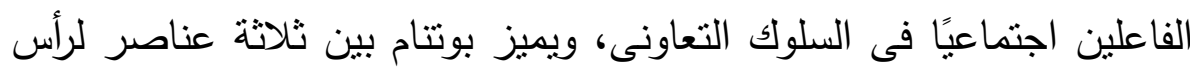


المال الاجتماعى هى: الثبكات، والمعايير، قواعد السلوك، والثقة، وكلها تساعد

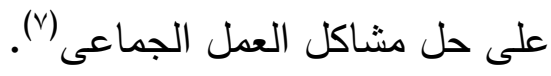
يفهم رأس المال الاجتماعى على المستوى الفردى بوصفه "الموارد

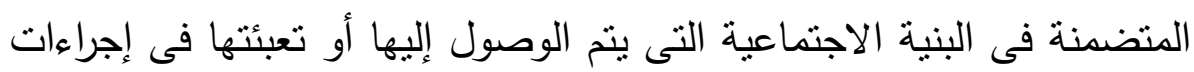
قصدية"، وينأثز هذا النوع من رأس المال العلائقى بمدى موارد شبكة الفرد التئه

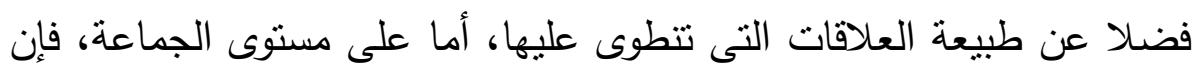

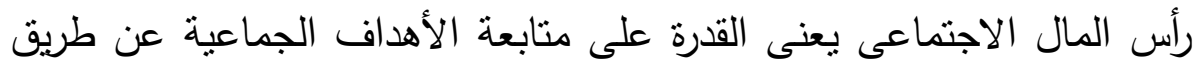

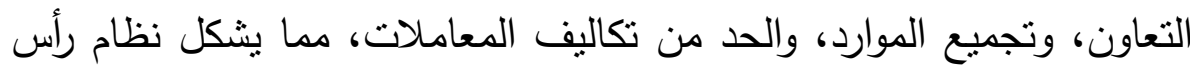

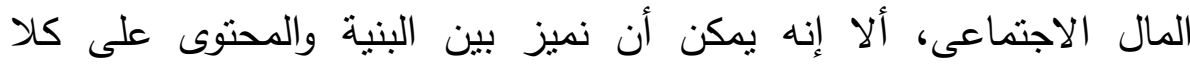

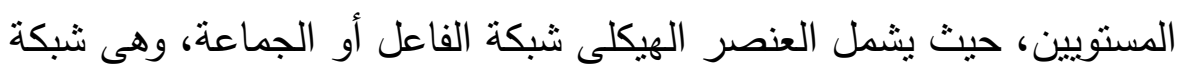

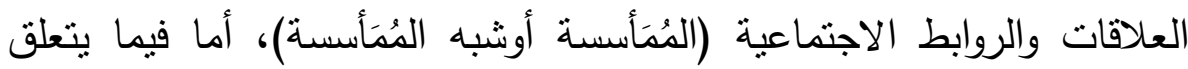

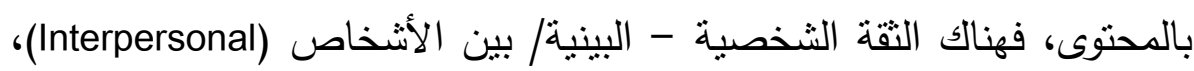

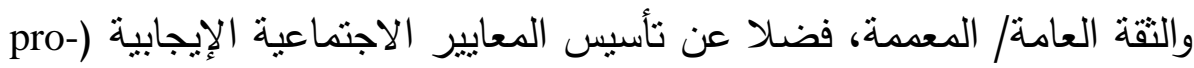

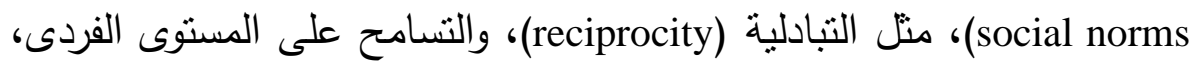

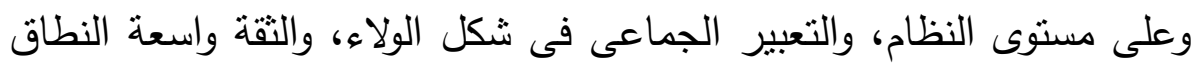

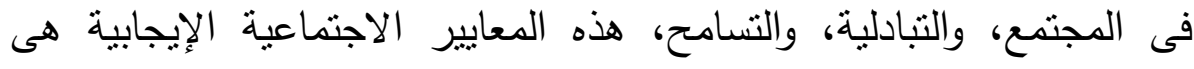

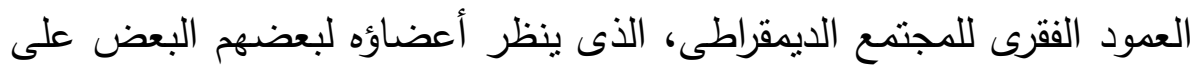
أنهم أحرار ومتساوون (^). بناء على ألكسيس دى توكفيل وجون ستيوارت ميل يفترض أن يتم

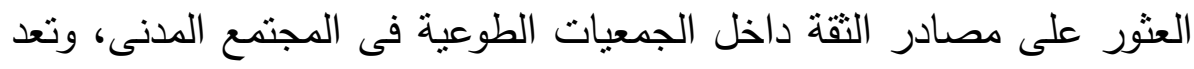
هذه الثبكات ومعاييرها وممارساتها للتعاون كأساس للمنظمات الرسمية منل 
الأحزاب السياسية التى تقوم بتجميع تفضيلات الأفراد، وبما أن هذه الجمعيات

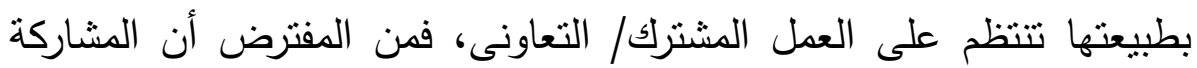

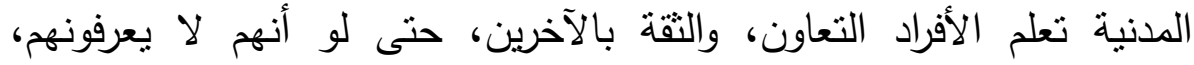

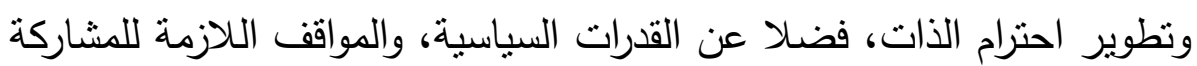
فى الساحة الديمقراطية(9).

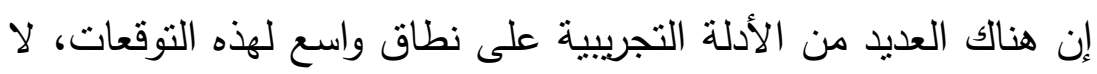

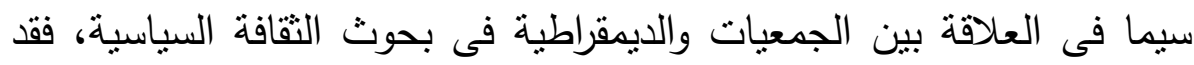
أكتثف ألموند وفيربا مستوى أعلى -بشكل واضح - من التقة بين الأشخاص

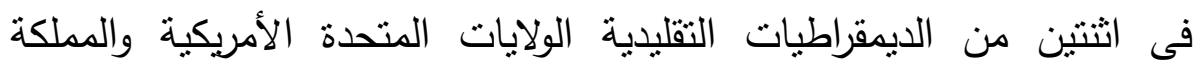

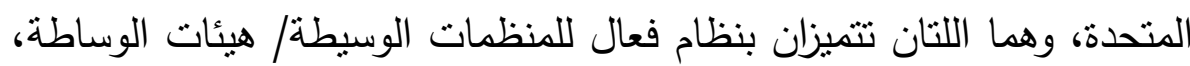

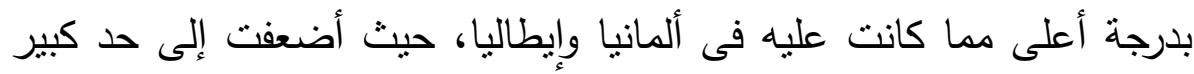

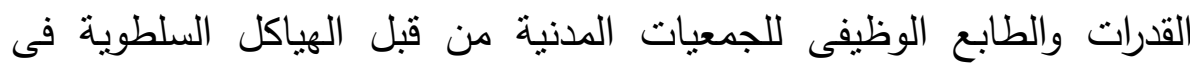

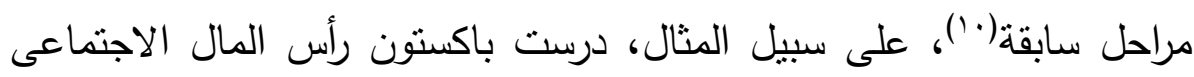

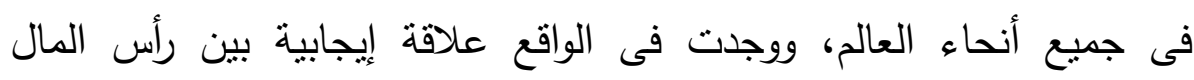

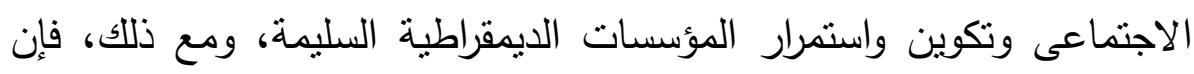

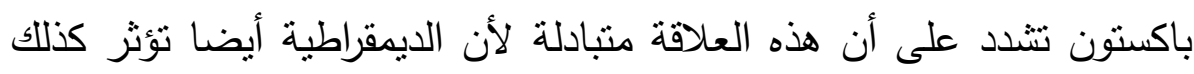

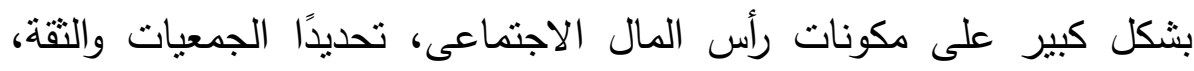

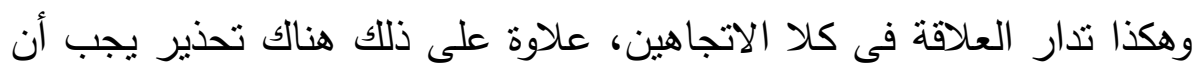

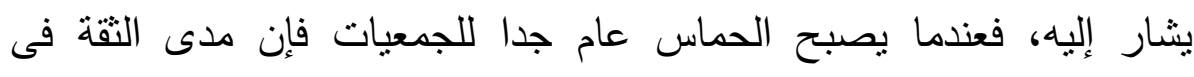

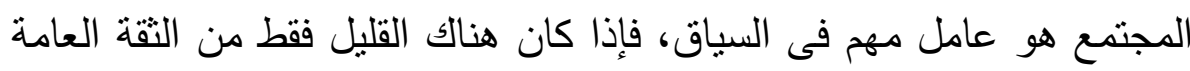

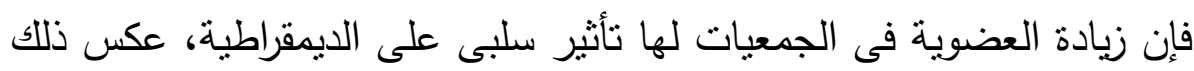




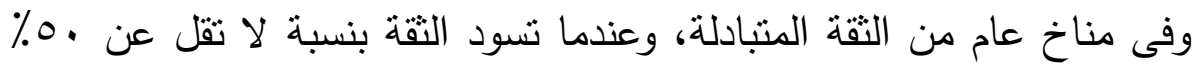

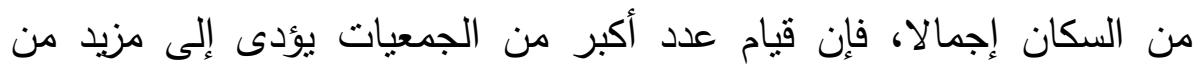
الديمقراطية ، ذلك أن الجمعيات فى مناخ من عدم النقة يحتمل أن تكون خطرة

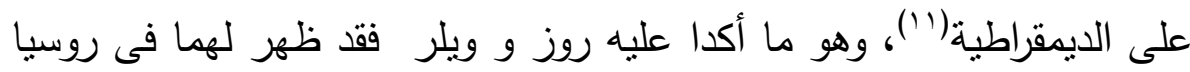

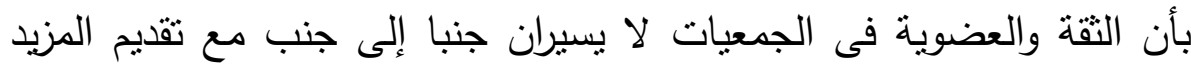

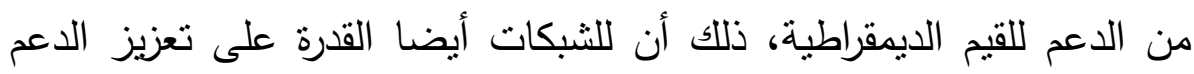

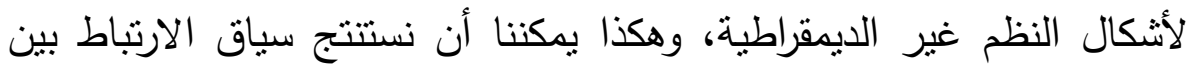

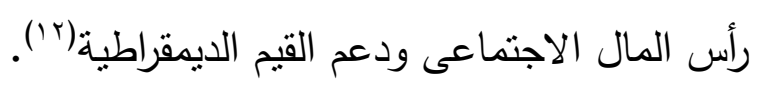

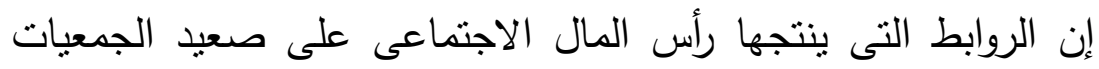

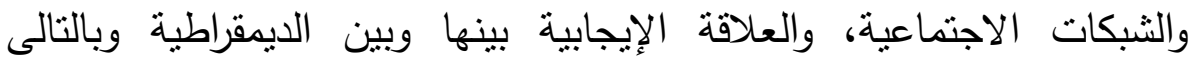

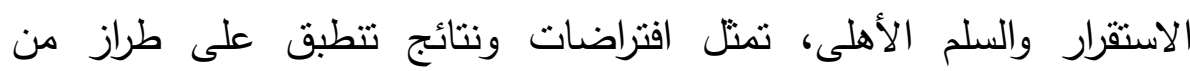

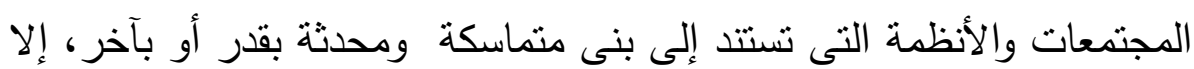

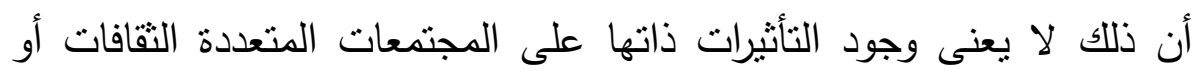

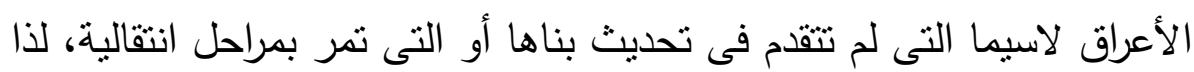
اتجه عدد من الباحثين إلى دراسة رأس المال الاجتماعى الذى يتم إنتاجه داخل

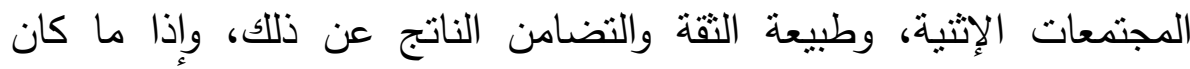

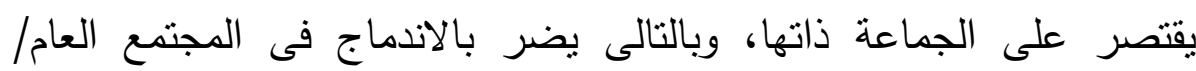

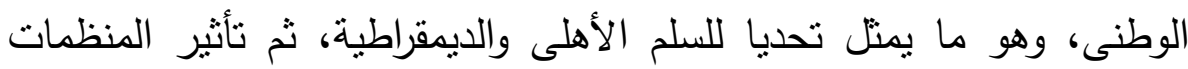

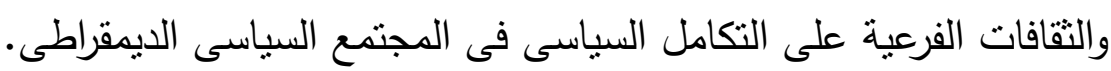




\section{با - الشبكات والموارد الناظمة للتنوع الإثنى}

خلصت عدد من الدراسات المهمة إلى أن رأس المال الاجتماعى نظرية لا لالئي

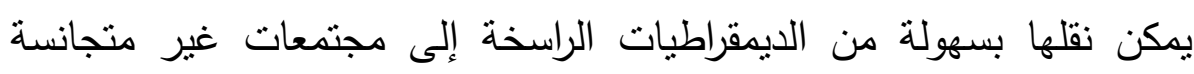

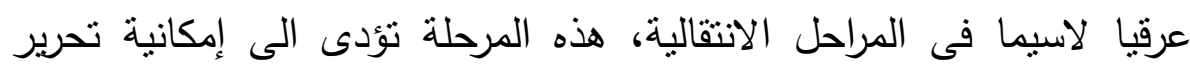
الأقلات وكذللك اضطهادهم، من أجل مواجهة تحديات أو مبررات مثل تأمين

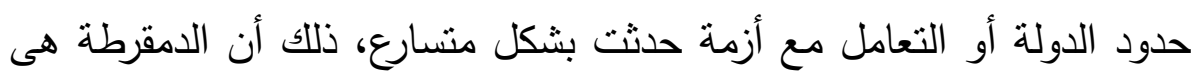

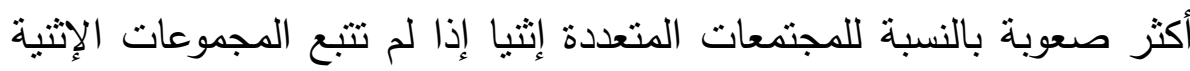

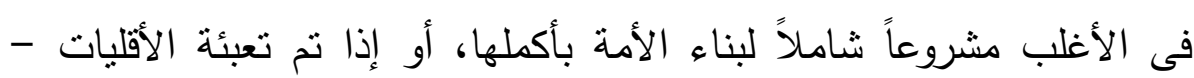
بسبب وجود تاريخ من الظلم ضدهم - بطريقة تهدد الوحدة الوطنية(r').

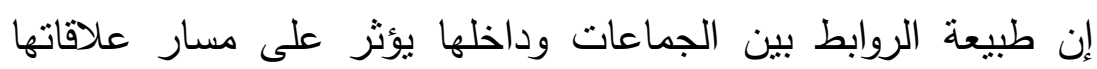

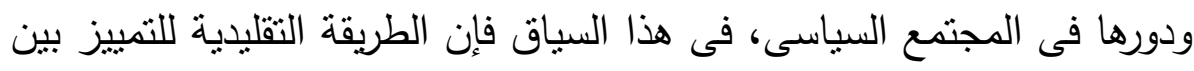

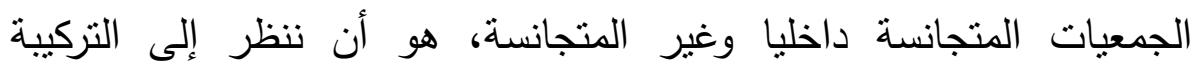
الاجتماعية الداخلية الخاصة بها، وهذا هو اقتراب بوتتام وتميزه بين الرأسمال

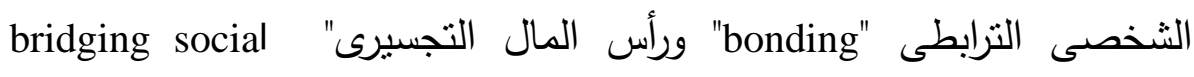
"capital

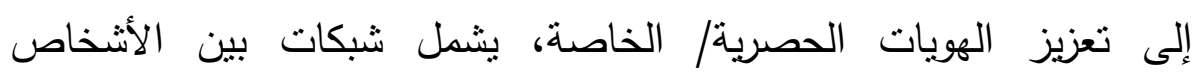

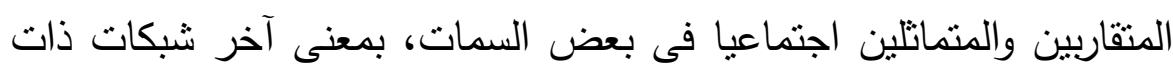

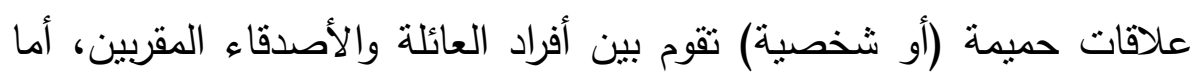

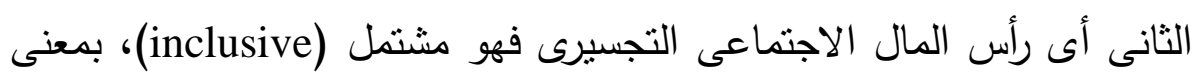

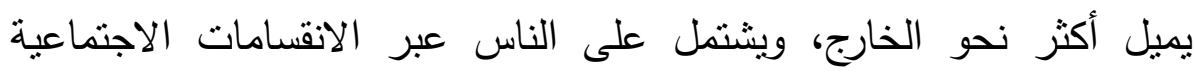


المختلفة، ممثلا لثبكات أقل حميمية، كما فى علاقات العمل، وفى علاقات

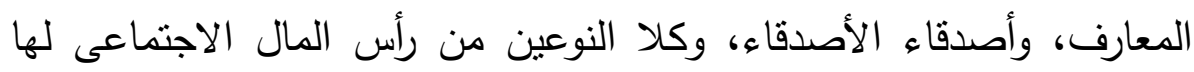
صفات متباينة، فرأس المال الترابطى يخلق ولاء قوى فى المجموعة، وهو جيد الئ للعلاقات التبادلية تحديدا، ويمكن أن يوفر الموارد الاجتماعية والنفسية للفئات

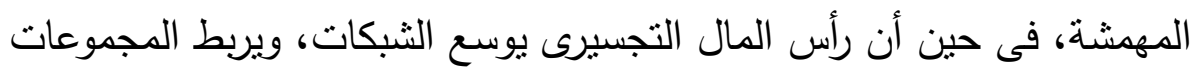
بالموارد التى يحتاجونها، والتى خلافا لذلك قد لا نجدهم قادرين على الوصول إليها، لذا يحاول بوتتام تجنب الحكم على هذين النوعين من رأس المال

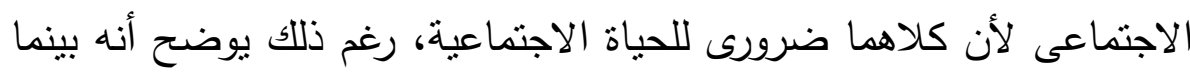

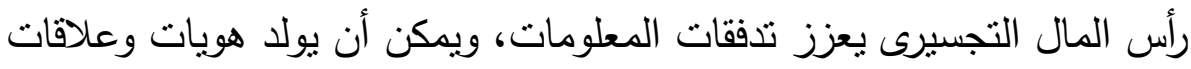

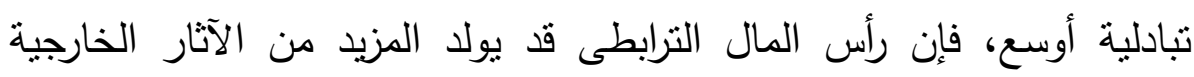

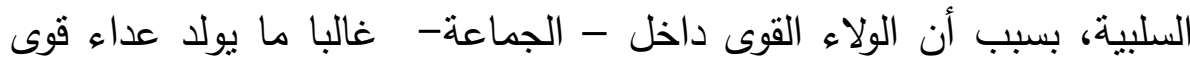

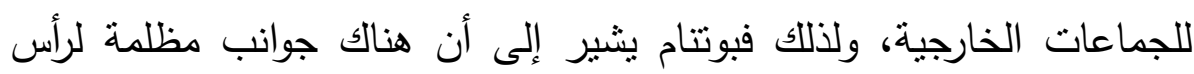

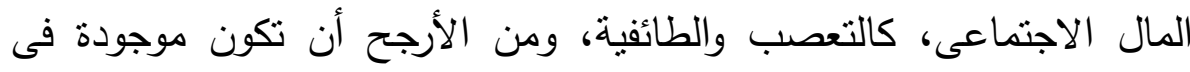

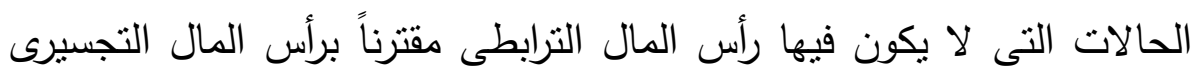

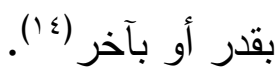

تتئر العديد من الدراسات فى هذا المجال إلى تحليل فارشنى عن الحالة

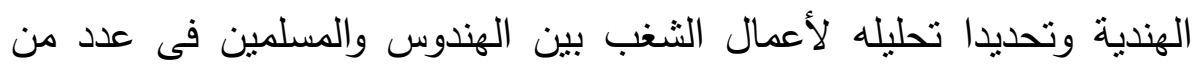
المدن الهندية، حيث أعنبر أن الفرق الذى يؤخذ فى الحسبان بين السلام

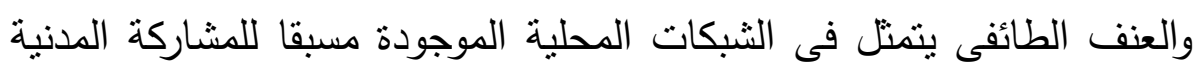

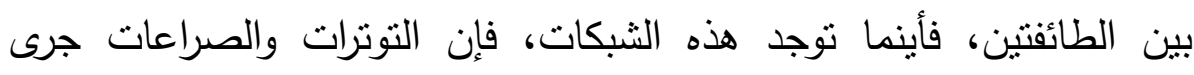

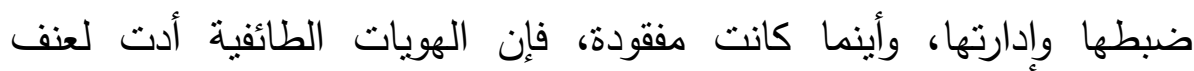


مستترى ومروع، هذه الثبكات وفقا لله يمكن تقسيمها إلى قسمين: الأطر الجمعياتية لمشاركة "associational forms of engagement"، والأثكال اليومية للمشاركة، حيث تقوم الأطر الجمعياتية على هياكل تتظيمية، أما الثانية

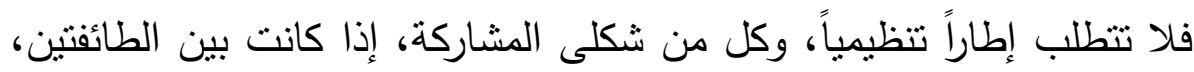

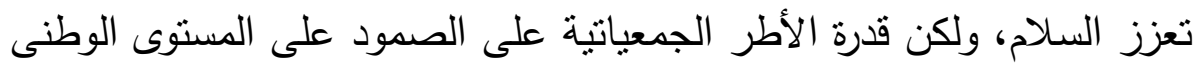

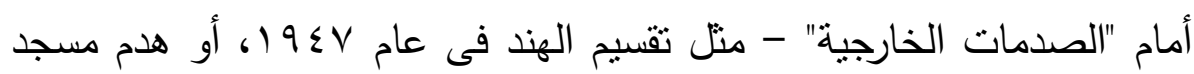

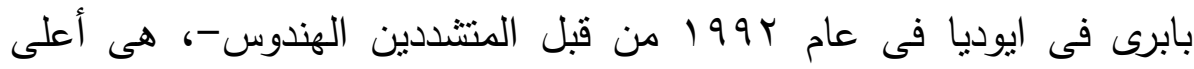

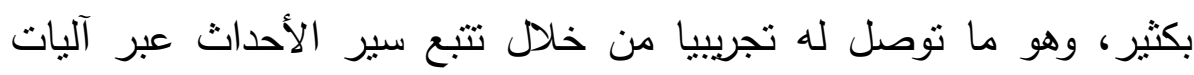
مختلفة، حيث نوصل إلى أن تعزيز التواصل بين أعضاء الجماعتين الدينيتين المختلفتين، والثبكات المدنية، غالبا ما تجعل السلام على مستوى الأحياء المتجاورة ممكنا، كذلك فإن المشاركة الروتينية/ النمطية تتيح للناس العمل معا،

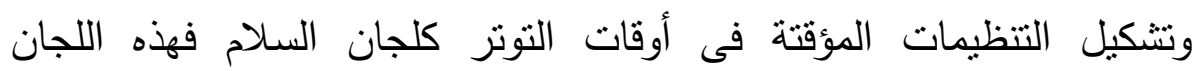
أصبحت مهمة للغاية، فهى تراقب الأحياء، وتكتتف الثنائعات، وتقدام المعلومات إلى الإدارة المحلية، وتسهل التواصل بين المجتمعات المحلية،

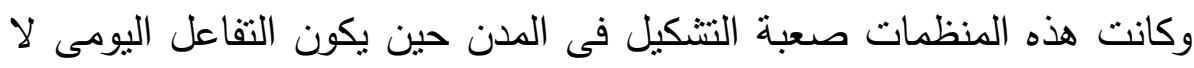
يتجاوز خطوط الانقسام الدينية، أو حيث يعيش الهندوس والمسلمين في أحياء

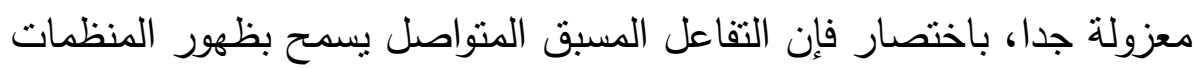
المناسبة لإدارة الأزمة (10) على صعيد آخر فإن أهمية الجمعيات تزداد على صعيد المجتمع لإدار

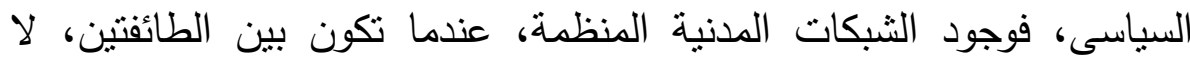
يقتصر دورها على مواجهة الصدمات الخارجية، ولكن أيضا تكون مقيدة 
للسياسيين المحليين فى السلوك الاستراتيجى بتشكيل قوة تعويضية مقابلة، فإذا

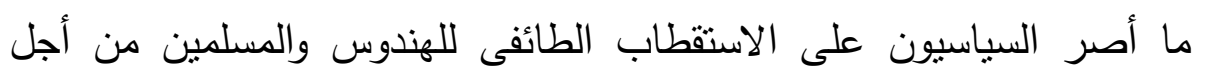

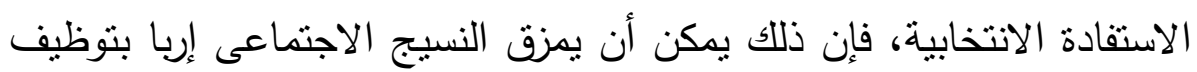

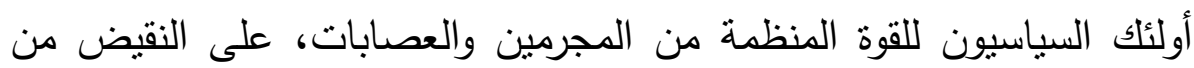

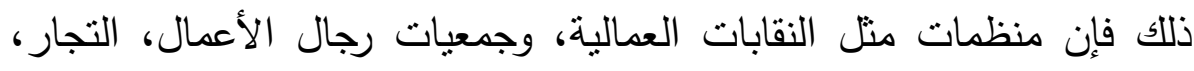
المعلمين، الأطباء، والمحامين، وعلى الأقل بعض الأحزاب السياسية ، تتكامل ولئل بشكل جماعى، ويتم إنشاء قوى تعويضية مقابلة(1').

إن النساؤل الذى يثار فى هذا المجال، هل الجمعيات الإثثية يمكن أن تسهر الإئية

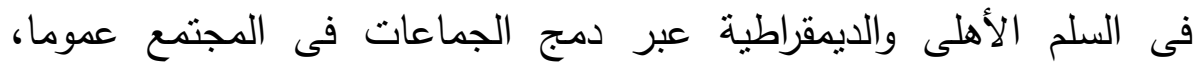

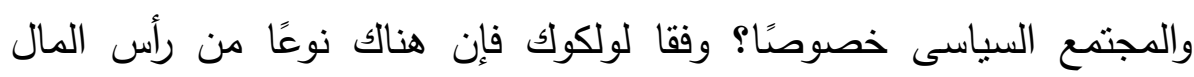

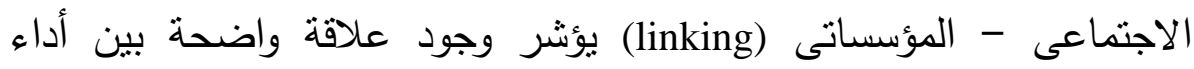

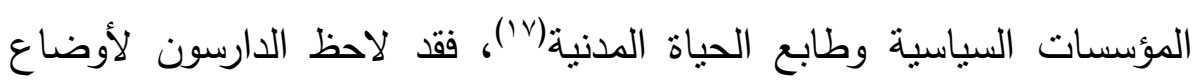

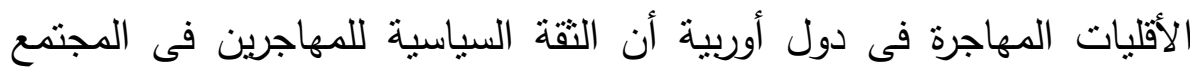

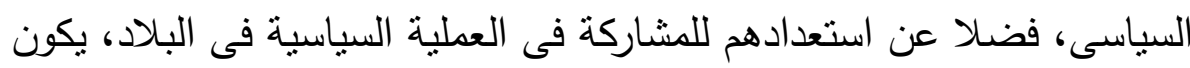
أقوى بين أولئك الأفراد الذين هم أعضاء في جماعة إثتية منظمة تنظيما داخليا

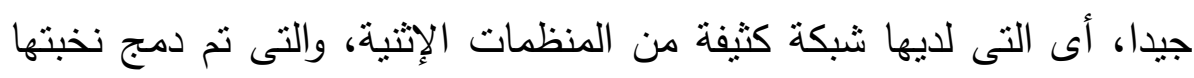

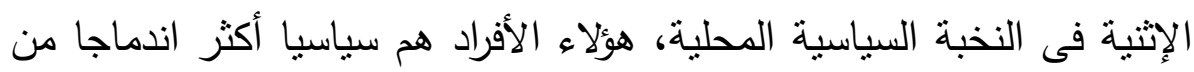

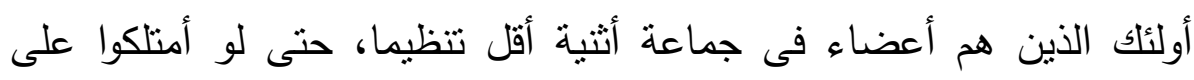

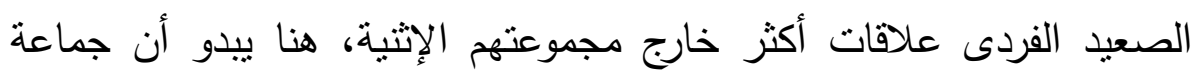


إثثية منظمة تتظيما جيدا ومتكاملا، تعمل كجسر تعزيز للتكامل السياسى لأعضائه|(') (1).

فى سياق مواز فإن النقة الاجتماعية داخل المجتمع المحلى إذا ما تكاملت النخب، يمكن أن تتخطى إلى الثقة فى المؤسسات السياسية المحلية،

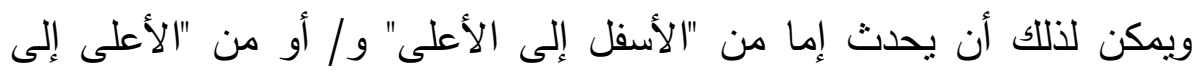

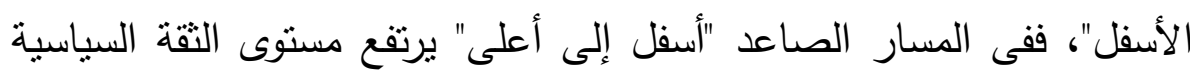

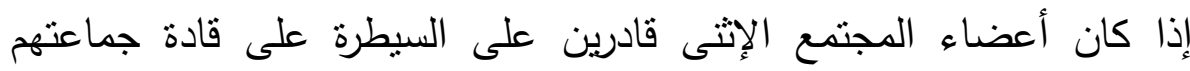

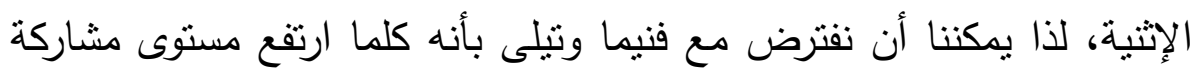

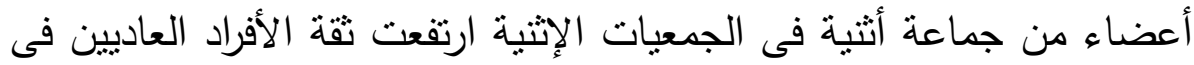

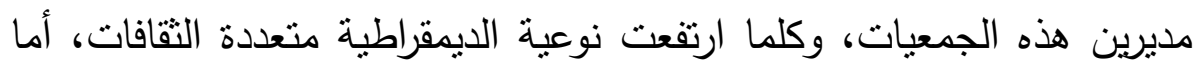

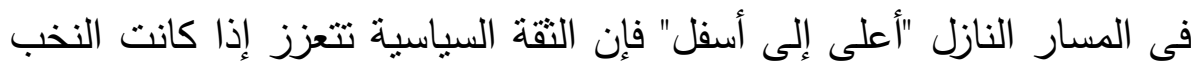

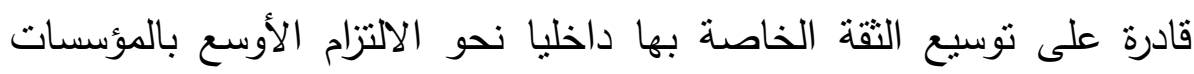

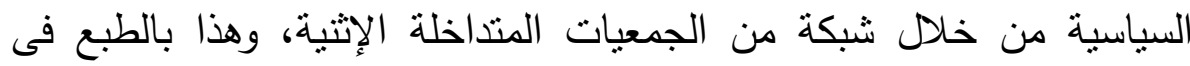

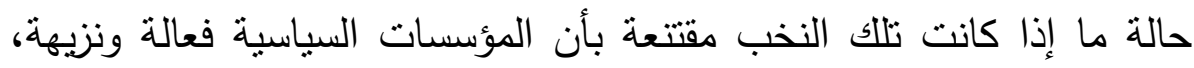
بمعنى أن فعالية وكفاءة المؤسسات ترتبط بقدرتها على تحقيق المعايير المطلوبة، وهو ما يعزز الثقة بهاب(19).

فضلا عن ذلك فإن انفتاح الحكومة تجاه مطالب المجموعات الإثتية يؤثر بالتأكيد على مدى الدعم للمؤسسات السياسية من قبل النخب الإثثية،

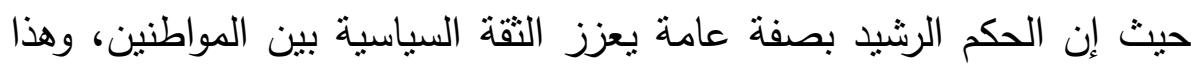

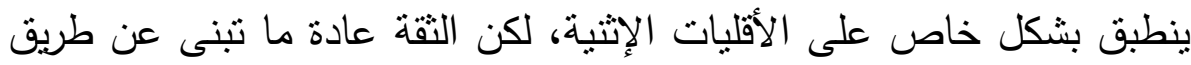

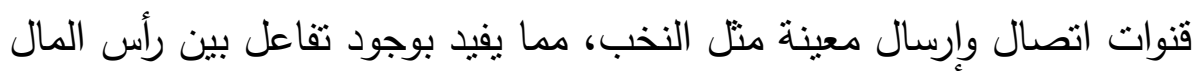


الاجتماعى على المستوى الفردى ورأس المال الاجتماعى على مستوى

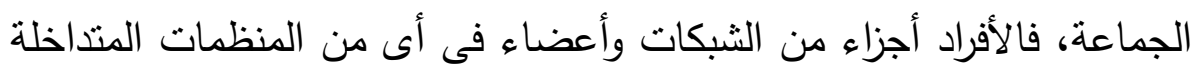

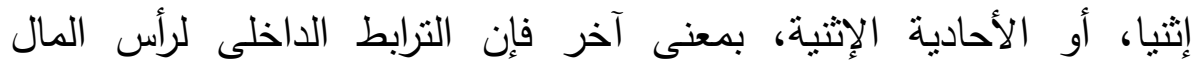

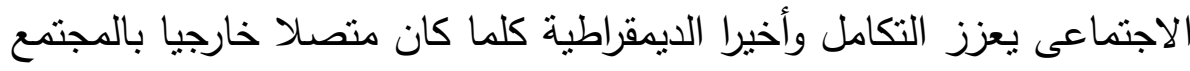

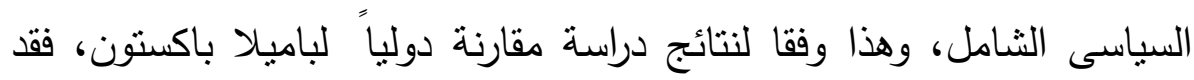

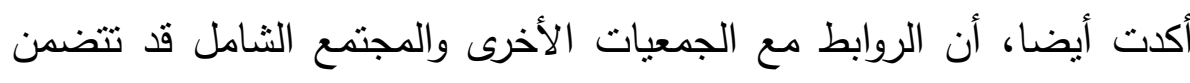

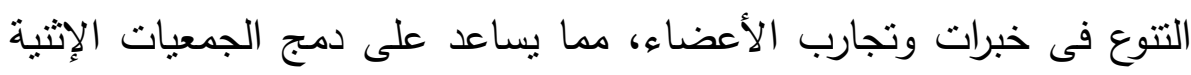

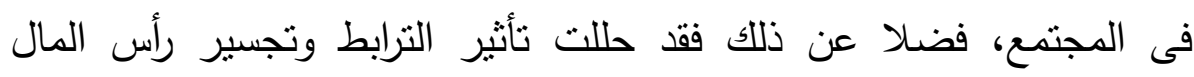
الاجتماعى على الاتجاهات الديمقراطية مع مساعدة من بيانات مسح القيم

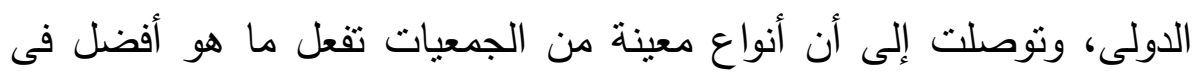

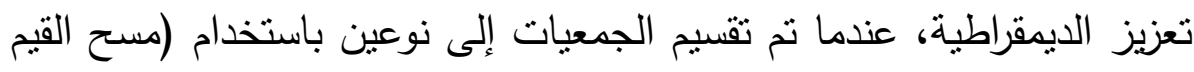

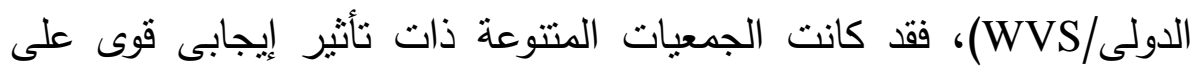

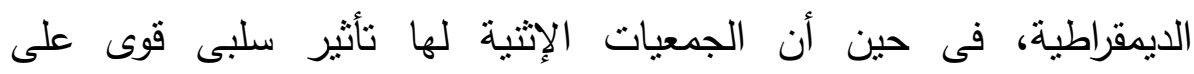
الديمقراطية(·) (r).

فى سياق مواز فإن الثبكات الثخصية المتمانتة إثثيا نعزز التفاعلات

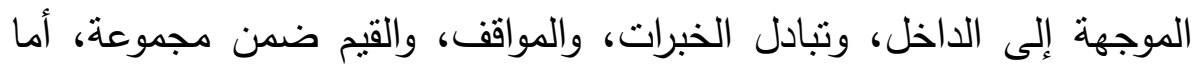

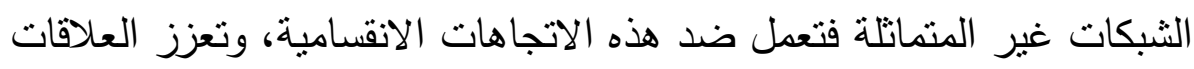

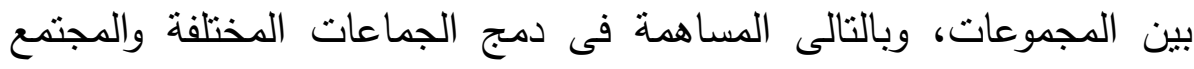

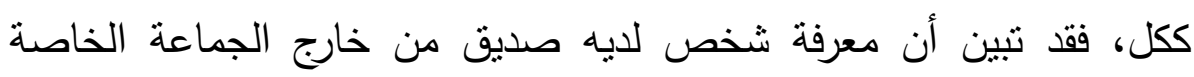

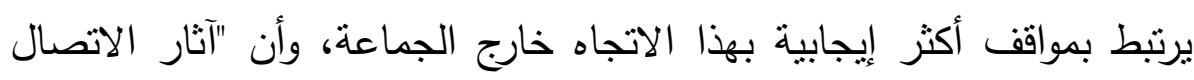

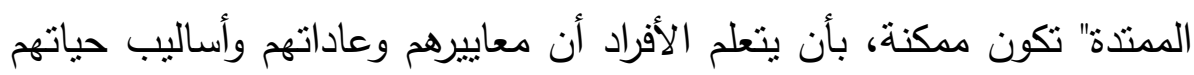


ليست هى الإمكانية الوحيدة للتعامل مع العالم الاجتماعى، إذا تم تجاوز

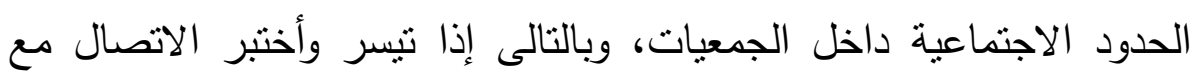

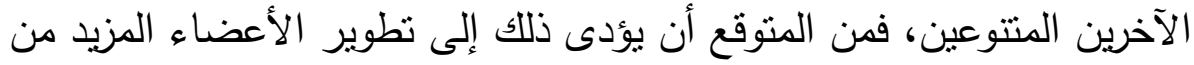

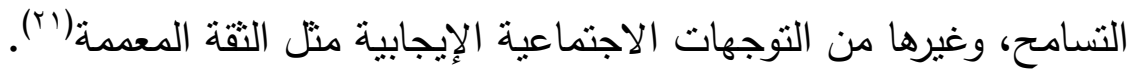

\section{ثانيا: الأطر المؤسسية للتنوع و السلم الأهلى الدي}

أكدت الدراسات السابقة على السمة الليبرالية للمؤسسات، فكما يتم تتظيم المجتمعات الإثثية داخليا من قبل جمعيات منتوعة الارتباطات، كذلك تتكامل

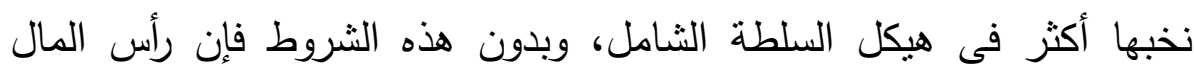
الاجتماعى الإثنى يمارس تأثيرًا ضارًا على السلم الأهلى والديمقراطية، وتكون الميول الأكثر احتمالا هى الاغتراب أو الانفصال.

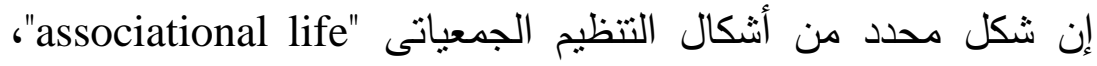
والتى يمكن أن تصور بذاتها كثبكة تتميز بعلاقاتها المحددة، تؤطر التفاعلات

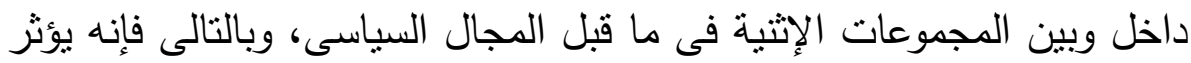

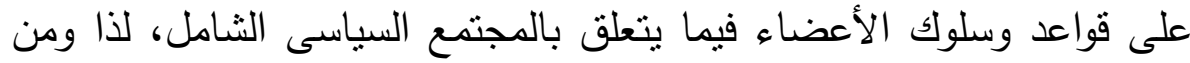

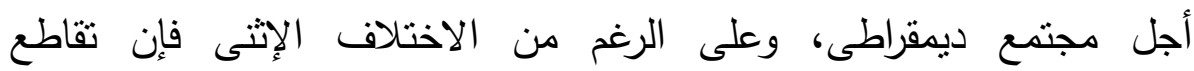

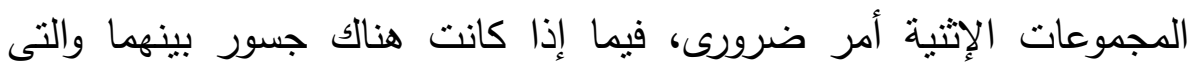
توصل لثعور شامل بالمجتمع السياسى (rr). أما على صعيد الأنظمة السياسية فعلينا أن نفرق بين الأطر المؤسسية

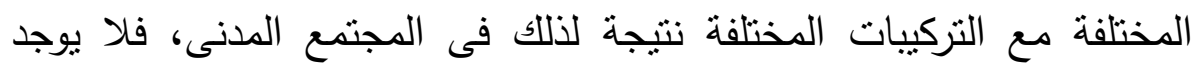

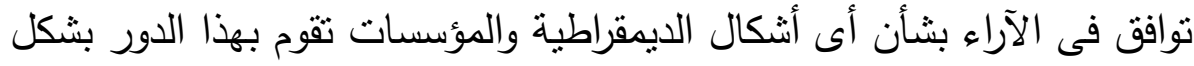


أفضل، وبشكل أساسى هناك نموذجان متتاقضان تماما من الديمقراطية تدعيان

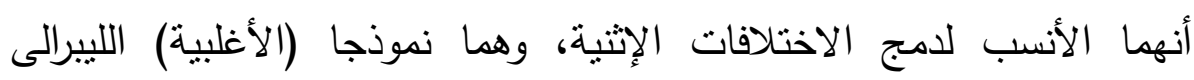

والنوافقية.

إن الأنظمة الليبرالية تتطلب مجتمعًا مدنيًا يندمج نسبيًا فيما يتعلق

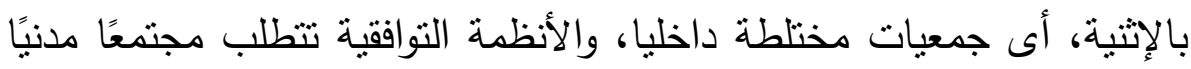

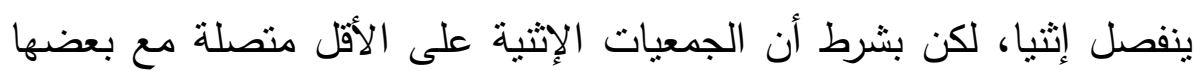

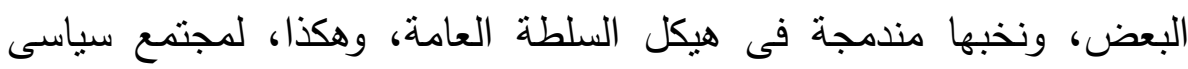

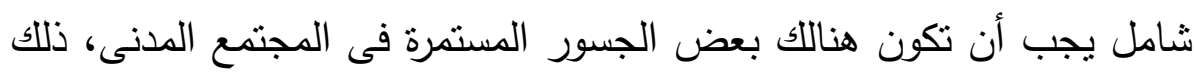

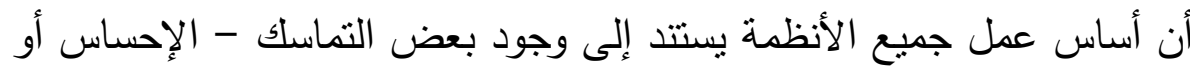

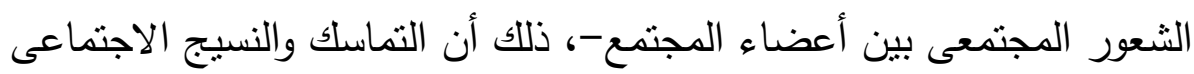

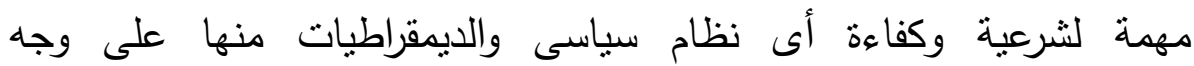
الخصوص، فالإحساس بالاتنماء للمجتمع يضفى الثرعية على النظام السياسى الثى كتعبير عن هذا المجتمع، ويجعل من الأسهل قبول قرارات الأغلبية، ويسهل عملية صنع القرار الجماعى من خلال ضمان استعداد الجماعات للتعاون ووجود شعور معين من التضامن، وبالتالى دعم الديمقراطية وتعزيز السلم

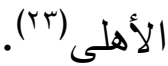
لذا فإن الإطار المؤسسى يرتبط من جانب بديمقراطية الأغلبية، ومن

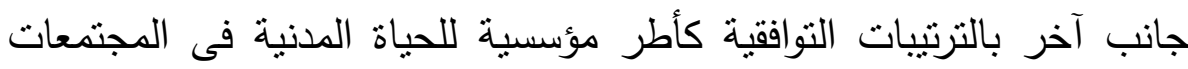
المنقسمة، لذا وفيما ينعلق بالإطار المعيارى، فإن التوقعات المفترضة من قبل

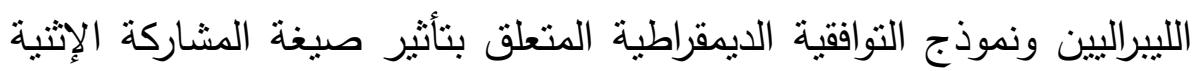
يجب أن تكون علاوة على ذلك منباينة. 
تستتد الليبرالية إلى شرعيتها من خلال القبول من جميع أعضاء المجتمع

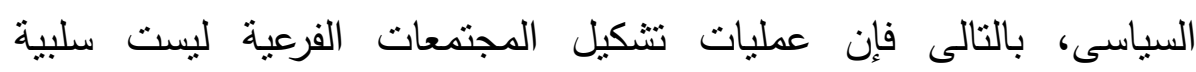

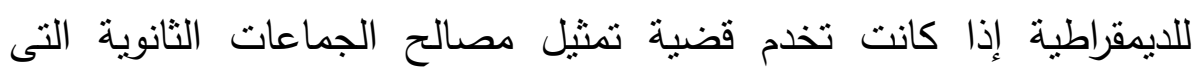
تهششها الثقافة السائدة، حتى إذا ما أدى ذلك على إنى المدى القصير إلى نتائج

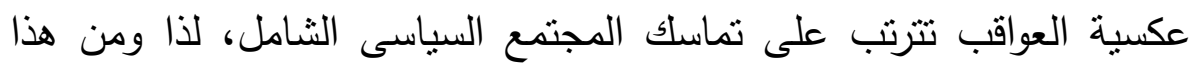

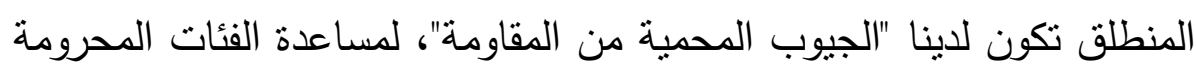

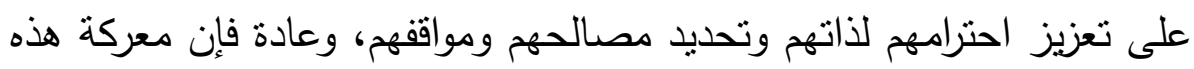
الجماعات ضد التمييز لا تكون ناجحة إلا بشكل جماعى، فعندما تكون

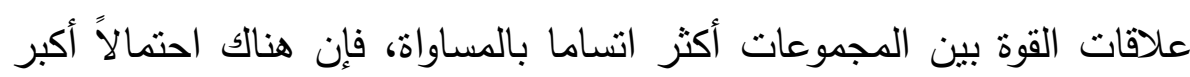

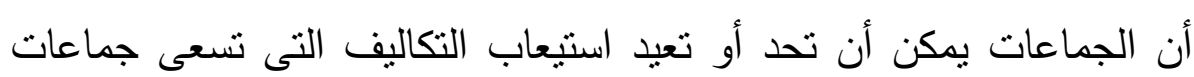

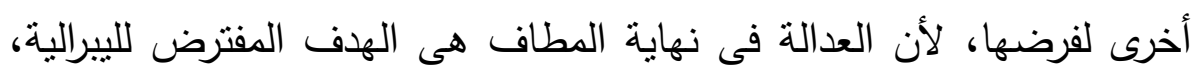

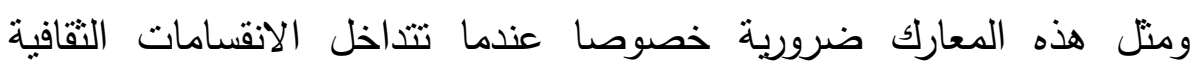
والاجتماعية والاقتصادية، فكلما كانت منل هذه المعارك تدور حول الاعتراف يتم إحضارها إلى الرأى العام، ويتم تضمين المزيد من الأفراد والجماعات

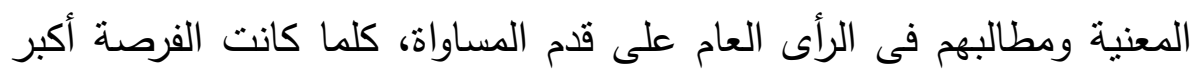

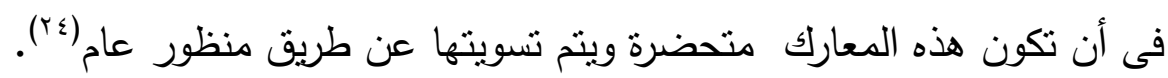

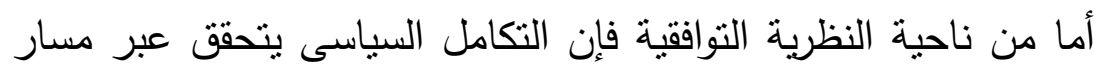

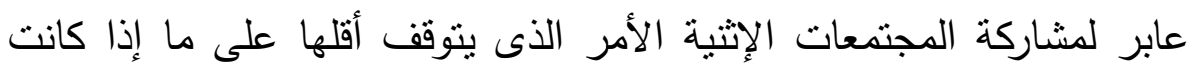

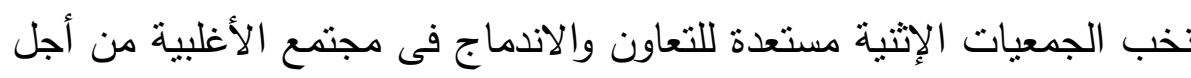

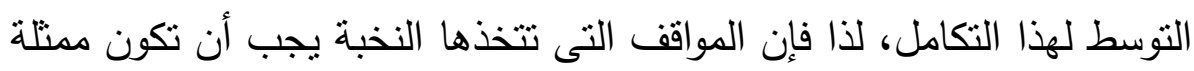

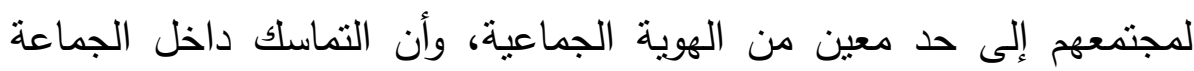


الإثثية ضرورى، ذلك أن الصراعات حول الأعراف التى نظهر دائما يتعين

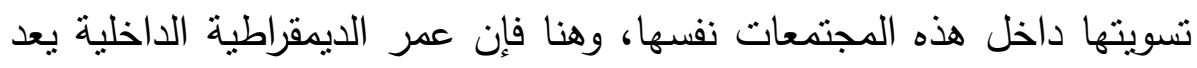
أمرا حاسما، وأن التثاور بين النخب والقاعدة يكون ذا معطى أفضل كلما يتم تتظيمها، ومن ثم فإن الممتلين يمكن مساءلتهم وكذلك نوعيتهم بالمتغيرات

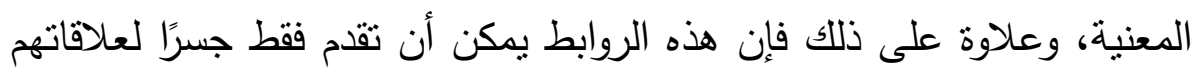

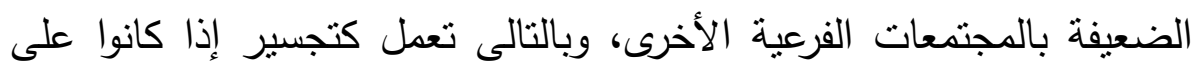

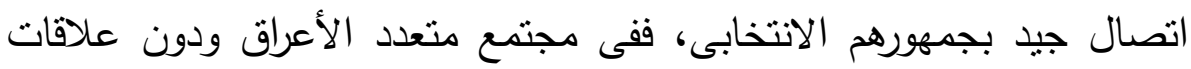

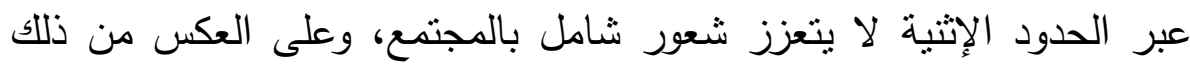

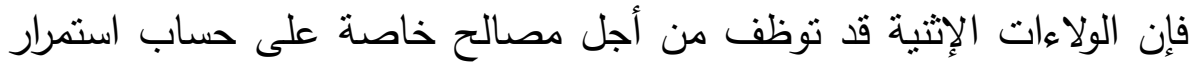

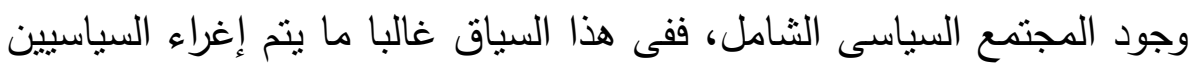
للعب بـ "البطاقة الإثنية" وتحريض الجماعات ضد بعضها البعض، والدخول

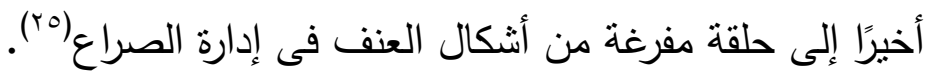

\section{ثالثا: السلم الأهلى والتنوع فى النظم الانتقالية}

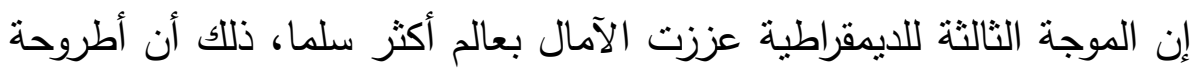

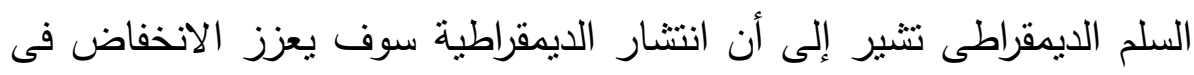

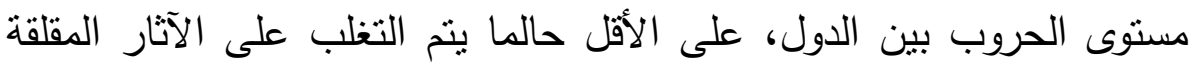

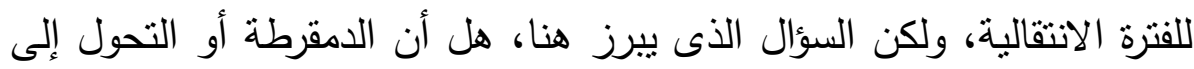

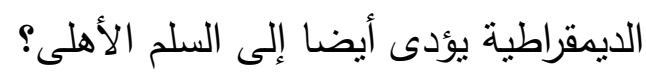

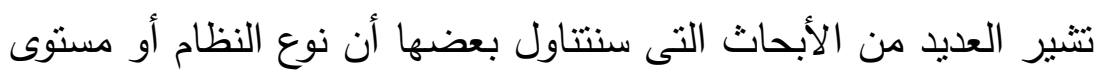
الديمقراطية ترتبط بالصراع الداخلى، وتركز جزء كبير من الأبحاث على نتيجة 
أن الأنظمة المركبة (الأنظمة الوسيطة بين الديمقراطية وحكم الفرد) تبدو أكثر ميلا للصراع الأهلى من أى نموذج منطرف (بَ).

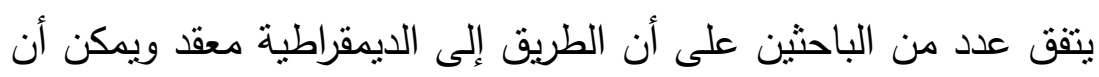

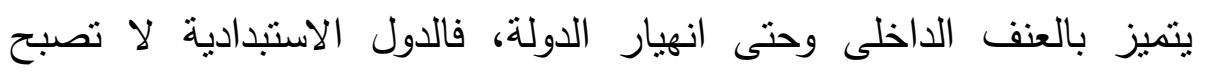

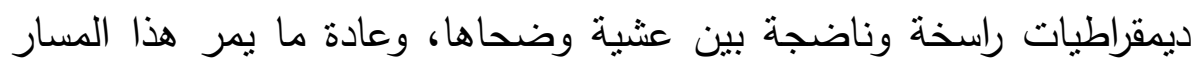

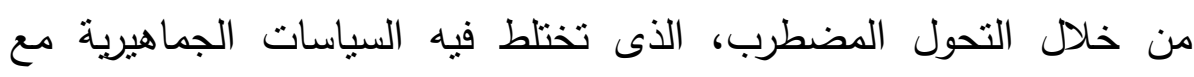
سياسة النخبة السلطوية بطريقة مضطربة، فالتغيير السياسى يقوض تماسك لكول

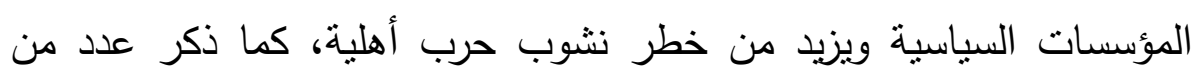

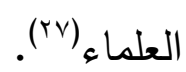

فالأنظمة شبه الديمقراطية التى تمتلك التتاقضات الكامنة نتيجة لكونها

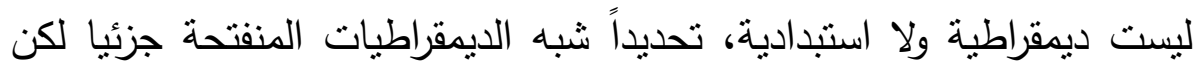
القمعية إلى حد ما، هو مزيج يدفع إلى الاحتجاج والتمرد، وغيره من أثنكال

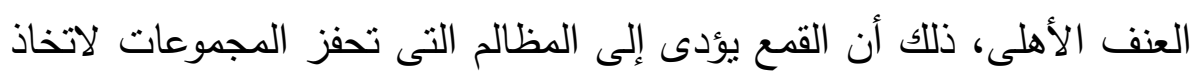

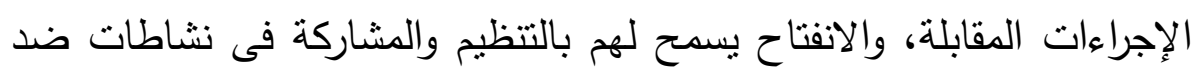

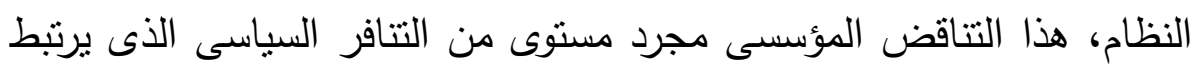

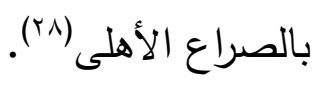
إن العنف السياسى كثير ما يقترن مع التحول إلى الديمقراطية/الدمقرطة،

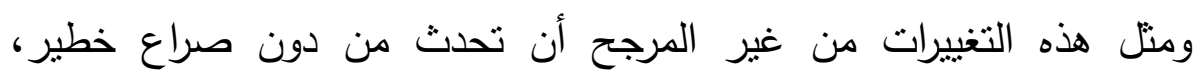

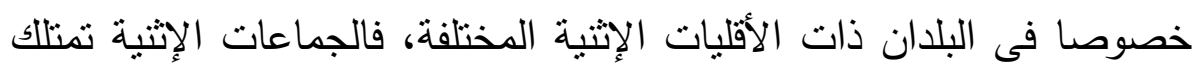

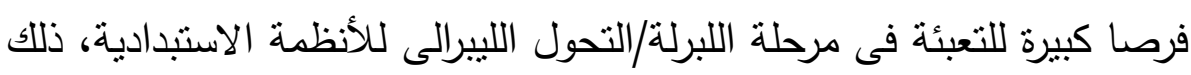

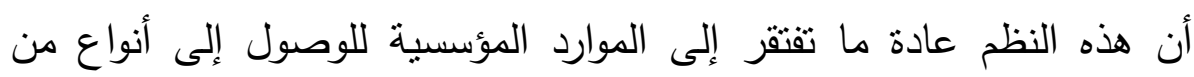


التكييف النموذجى للايمقراطية الراسخة، فعندما تتهار التسلطية وتتبعها جهود

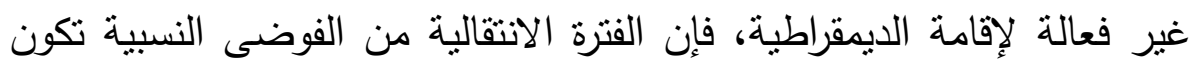

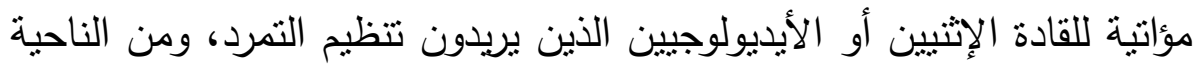

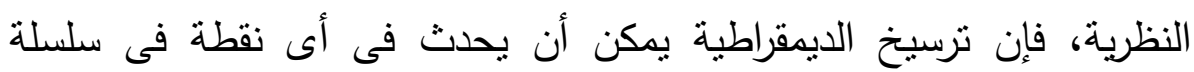

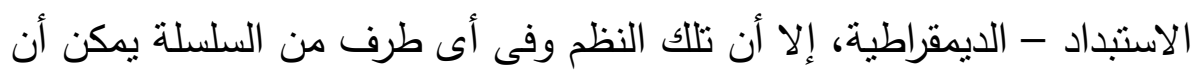
تنقام أو ألا تتقدم (ب9). فى هذا السياق أظهرت الدراسات أن وجود جماعة الأغلبية الواحدة،

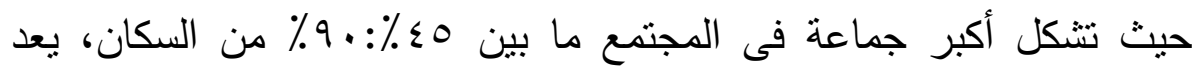
مشكلة خاصة، فالأغلبية المسيطرة غالبا ما تميل لقمع الأقليات، وتثكيل

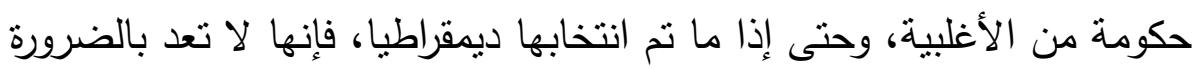
شرعية من قبل الأقلية، فى المقابل، فإن وجود مجموعتين من الحجم نفسه

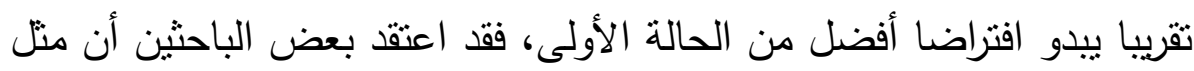

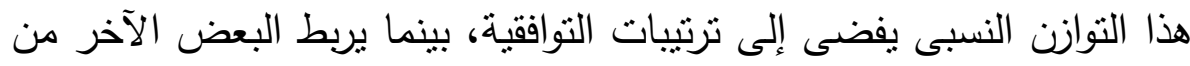

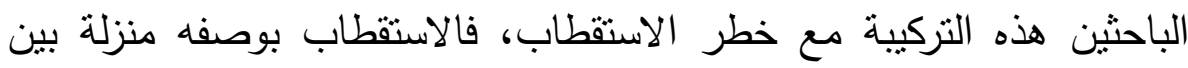

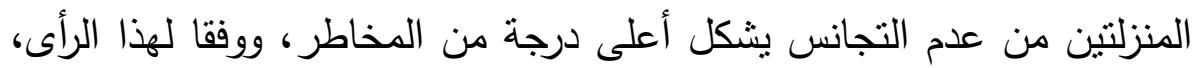

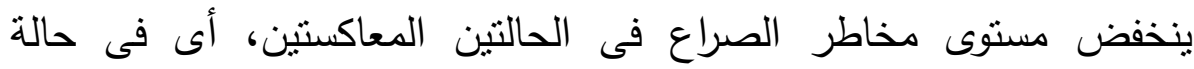
المجتمعات المتجانسة للغاية، وغير المتجانسة إلى حد كبير، ففى مجتى منمعات مجزأة للغاية، فإن الجماعات تكون أكثر ميلا إلى بناء تحالفات من مواجهة الى الى

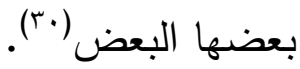
وفيما يتعلق بالتجانس الإثىى، يذهب الرأى إلى أن الجماعات الإثثية هى الإنى

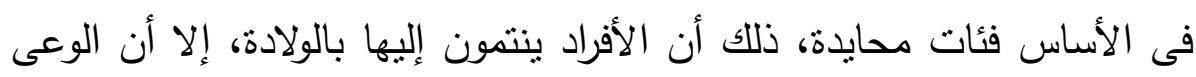


الإثنى "ethnicity" يمنل عاملا مركزيا فى تحويل الجماعات الإثثية إلى البعد

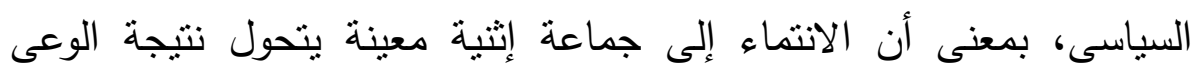

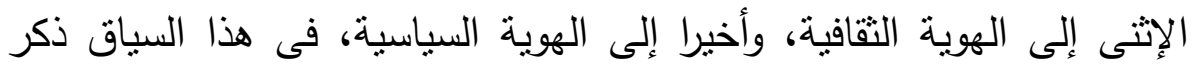

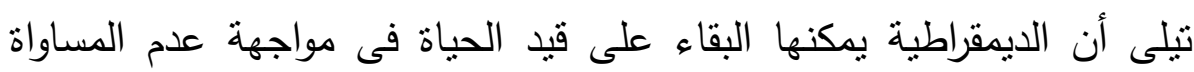

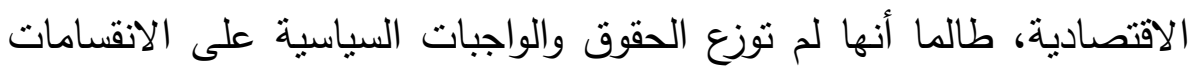

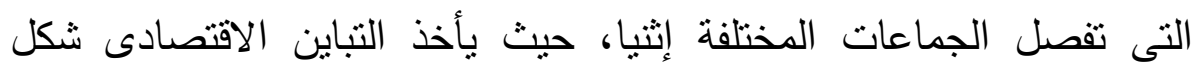

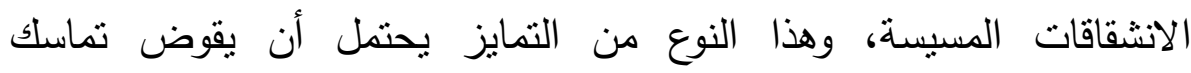

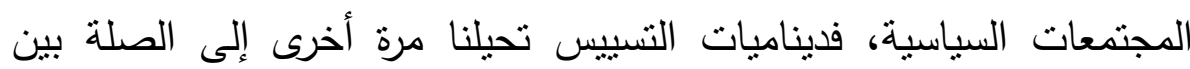
الهياكل، والجهات الفاعلة، والعمل الجماعى، فالنزاعات لا تتدلع تلقائيا بمجرد

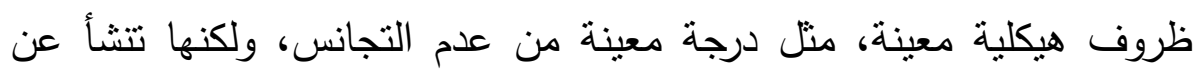

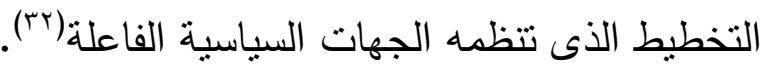

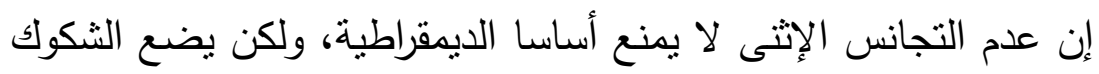

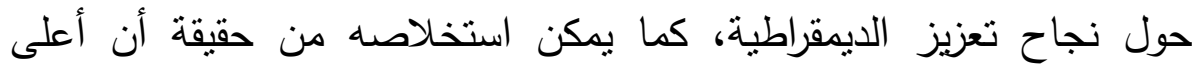

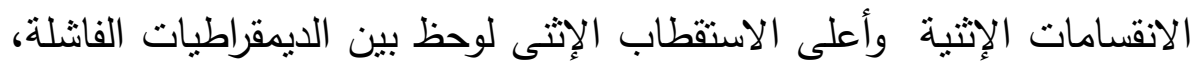

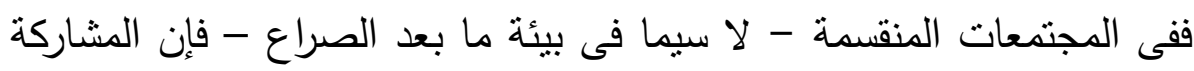

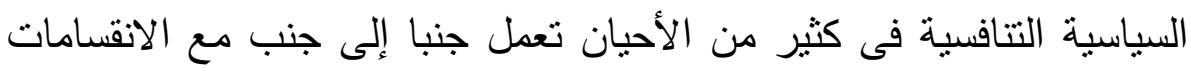

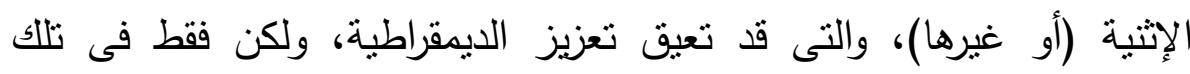

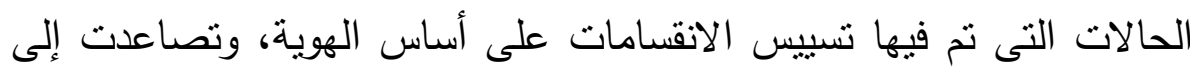
صراع عنيف انعكس سلبا على التجانس، فمن غير المرجح أن ينجح الانتقال الديمقراطى أو تعزيز الديمقراطية فى تلأك الدول(rr). 
إن ما تقدم يؤكد إمكانات الجهات الفاعلة أو الفاعلين، خاصة المجموعات التى تمثل مصلحة فصيل معين فى مجنمع غير متجانس، للنأثير

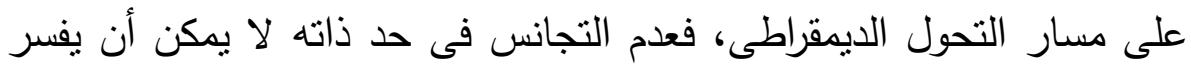
تصعيدًا فى الصراع، وليس من المرجح أن يؤثر بشكل مباشر على الشى الانتقال إلى الديمقراطية أو إخفاق الديمقراطية أيضا لا سيما فى الحالة التى يكون فيها الحد الأدنى الضرورى من المتطلبات الاقتصادية والثقافية والهيكلية للايمقراطية

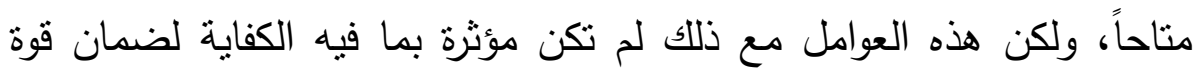
واستدامة الديمقراطية، فالجهات الفاعلة، والاستراتيجيات السياسية، والتحالفات، والقرارات ذات الصلة، يمكن أن تعوض للغاية عن الفجوة بين الظروف الهيكلية

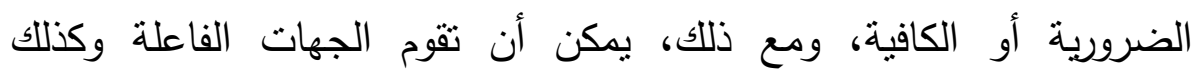
الكفسدين "spoilers" بتقويض عملية التحول الديمقراطى الجارية عندما نقرر أن تؤكد على تعزيز، ومأسسة، وتسييس عدم التجانس، لذلك علينا أن نتسأل

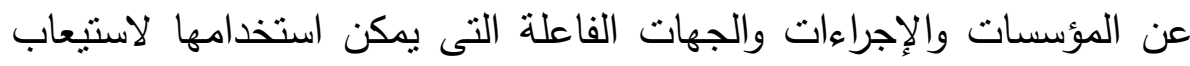
التباين، من أجل منعها من أن تصبح مسيسة وتمنع الطريق نحو الديمقراطية

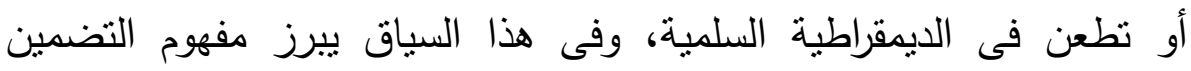

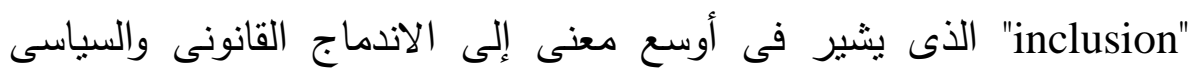

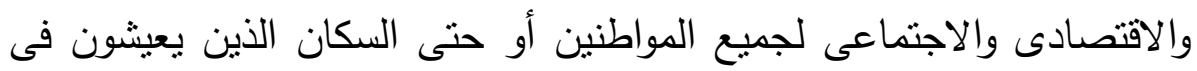

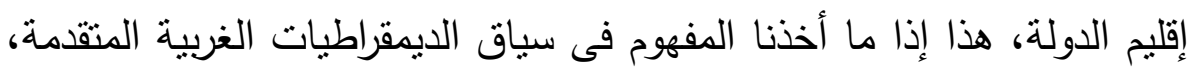

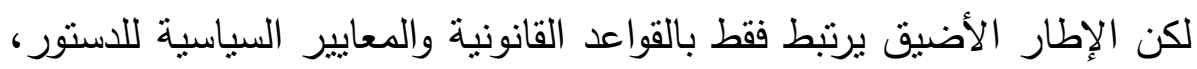
والإجراءات والمؤسسات السياسية، ووفقا لهذا التعريف الضيق، ينبغى لهذه 
الهياكل نوفير الضمان المؤسسى الذى يمنع حدوث التمييز القانونى والسياسى

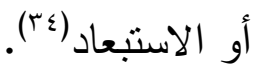

تقام الأدبيات المتخصصة عدة طرق للايمقراطيات للتعامل مع المطالبين

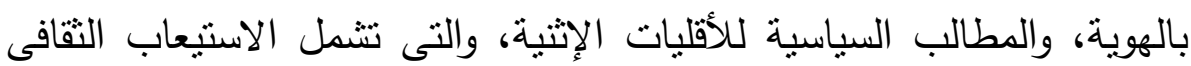
واللغوى، وذلك بمنح وتطبيق حقوق منساوية، أو منح حقوق مجموعة خاصة

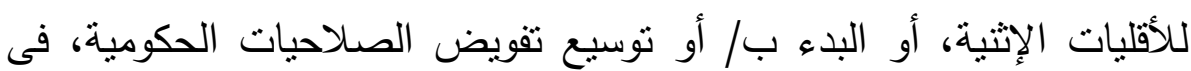
هذا السياق لا يقتصر جاك سنايدر فى تحليله على الديمقراطيات الراسخة فقط، لإنها

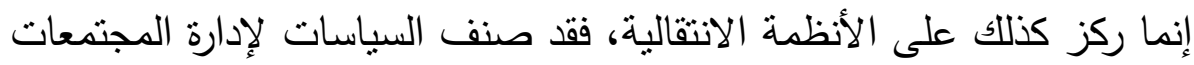
الديمقراطية المنقسمة إثثيا على طول اثثين من المحاور المتقاطعة، اعتمادا

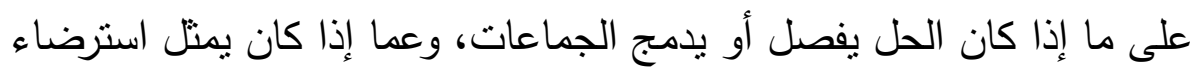

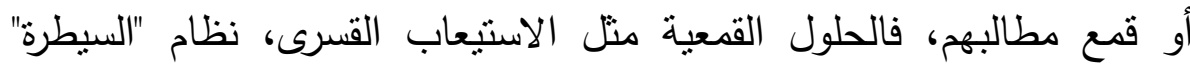

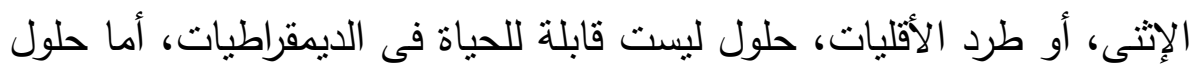
الاسترضاء فتتثل، التكامل عن طريق منح حقوق منساوية، والتعددية النقافية، من خلال منح حقوق مجموعة خاصة للأقليات، والفيدرالية الإثثية أو الحكم الذاتى، وهو خلاف ما ذهب له الفلاسفة اللييراليين والدستوريين الذين أصرو على أن التكامل فى الديمقراطيات يعنى أساسا المساواة بين جميع المواطنين

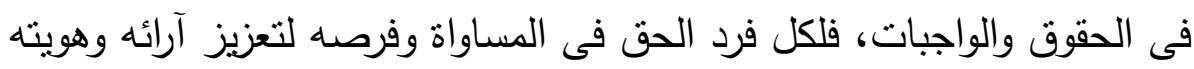

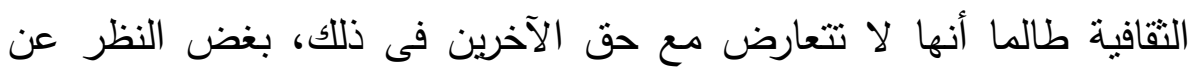

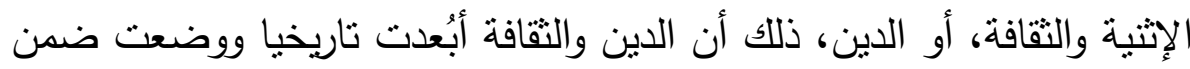

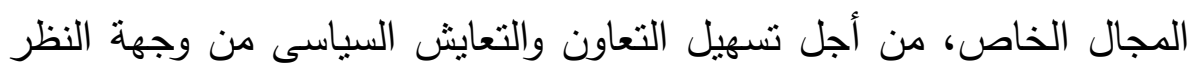
هذه(ro) 
أما دعاة وممنلو الإثثية واللغوية، والأقليات الدينية، فإنهم يعارضون

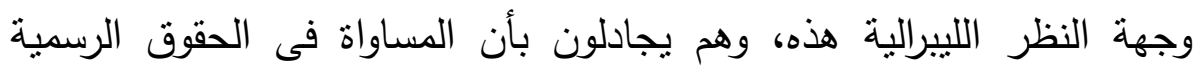

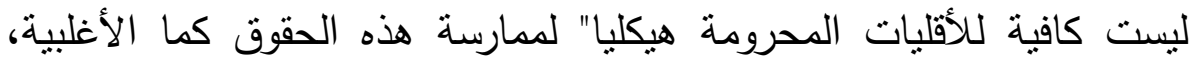

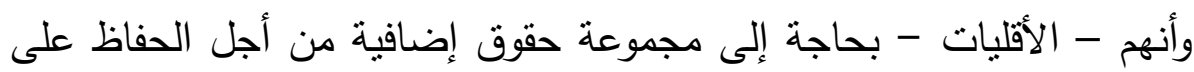

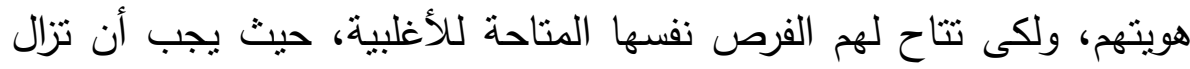

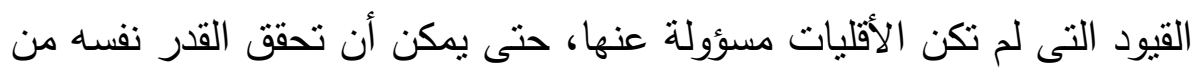
الحرية والمساواة التى تتمتع الأغلية بها فعلا، عليه فقد حدد ويل كمليكا ثلاثة الثانة أنواع مختلفة من حقوق الجماعة، وهى حقوق التعدد الإثتى " polyethnic rights"، وحقوق التمثيل الخاصة، وحقوق الحكم الذاتى، تعنى حقوق التعدد

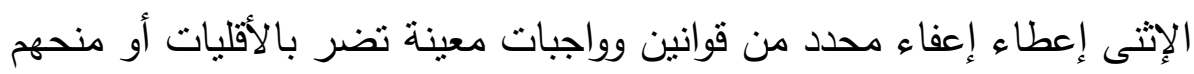

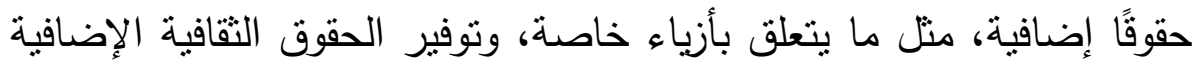

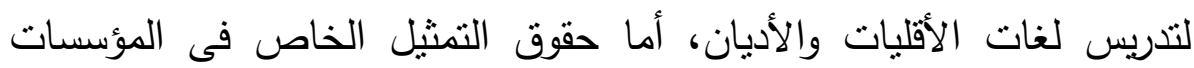
فتتشل مثلا الكوتا فى البرلمان أو الأنظمة الانتخابية أو فى السلطة التنفيذية، كما فى الديمقراطية التوافقية لليبهارت(ب0). نخلص مما تقدم أن تعزيز الهوية الثقافية دون الأخذ فى الاعتبار

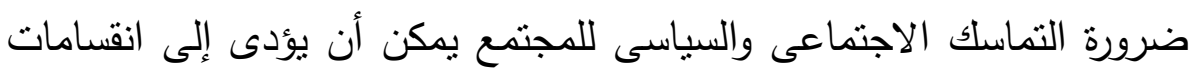

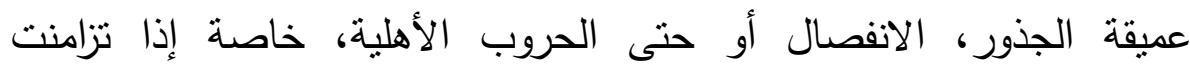

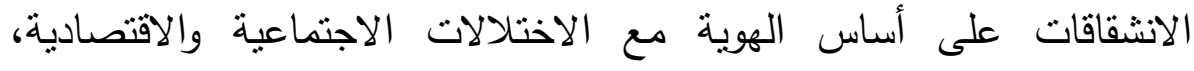

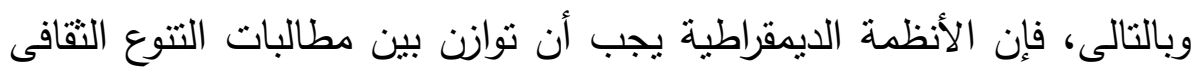

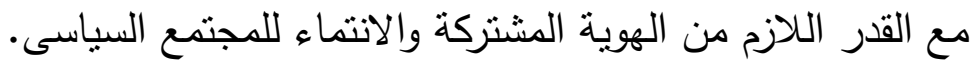




\section{خاتمستة}

إن أساس عمل جميع الأنظمة، يجب أن يتضمن قدرا من الإحساس بالانتماء

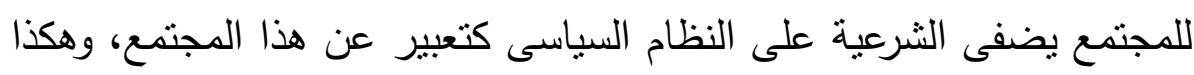

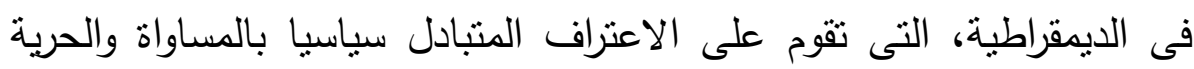

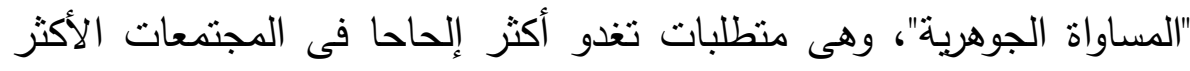
تتوعا، والأقل تجانساً، والأنظمة التى تمر بمراحل انتقالية، وفى العقود الأخيرة

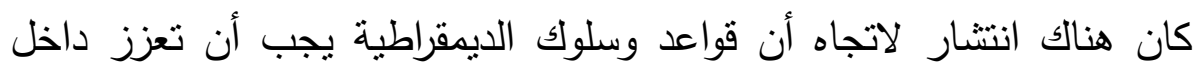

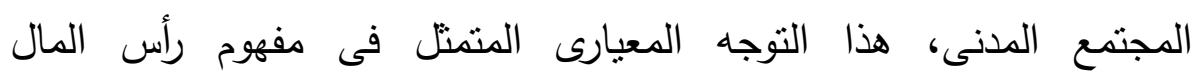
الاجتماعى، يمكن قياسه من خلال عدة مؤشرات، أهمها مدى التجانس والتقة

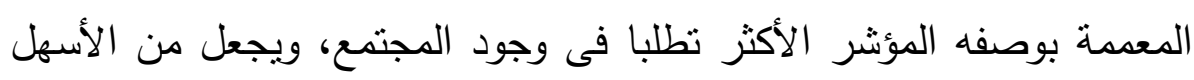

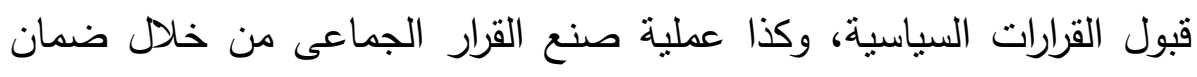

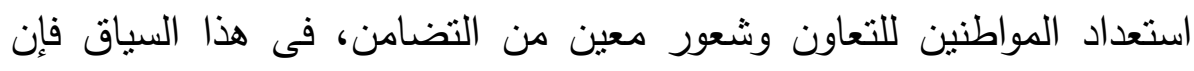

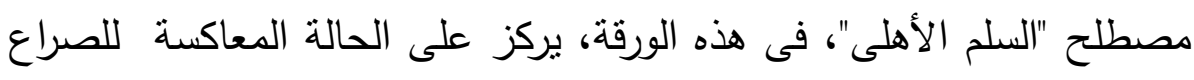

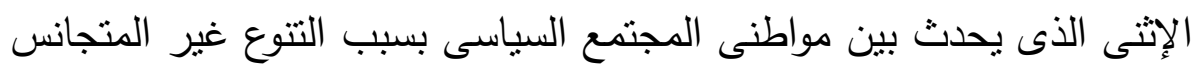

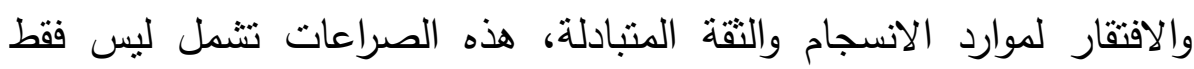

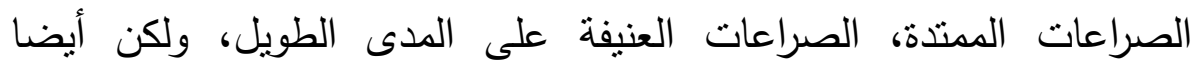

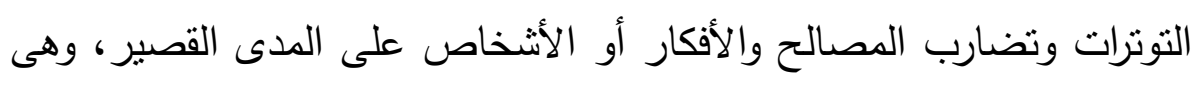

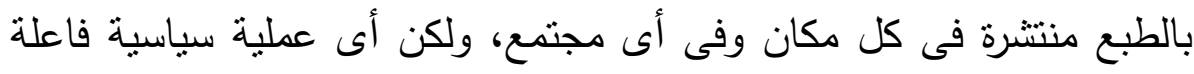
يجب أن تضمن حل النزاعات السياسية بالوسائل غير العنيفة. 


\section{المراجع}

1- https://en.wikipedia.org/wiki/List_of_countries_and_dependencies by population.

2- Clare Mar-Molinero and Miranda Stewart, (eds.), Globalization and language in the Spanish-speaking world: macro and micro perspectives (Great Britain: Palgrave Macmillan, 2006, p.48.

3- https://en.wikipedia.org/wiki/List_of_countries_and_dependencies by population.

4- James D. Fearon, Ethnic and Cultural Diversity by Country, Journal of Economic Growth, Vol. 8, No. 2 Jun., 2003, p. 205.

5- Pamela Paxton, Social Capital and Democracy: An Interdependent Relationship, American Sociological Review, Vol. 67, No. 2, Apr., 2002, pp. 254-277.

6- Partha Dasgupta and Ismail Serageldin,(eds.), Social Capital : A . Multifaceted Perspective, Washington DC: World Bank,1999, p.327.

7- Robert D .Putnam, Robert Leonardi, and Raffaella Y. Nanetti, Making Demcracy Work: Civic Traditions in Modern Italy, Princeton, Princeton University Press, 1993, p. 36.

8- Nan Lin, Building a Network Theory of Social Capital, in Ronald Burt et al. (eds.), Social capital theory and research, New York: Aldine de Gruyter, 2001, pp. 12-20.

9- Mark E.Warren, Democracy and Association, Princeton/ Oxford Princeton University Press, 2001, p. 40.

10- Gabriel Almond and Sidney Verba, The Civic Culture, Princeton, Princeton University Press, 1963, p. 298.

11- Pamela Paxton, Is Social Capital Declining in the United States? A Multiple Indicator Assessment, American Journal of Sociology, Vol. 105, No. 1, july 1999, pp. 107-117.

12- Richard Rose and Craig Weller, What does social capital add to democratic values, In Gabriel Badescu and Eric M Uslaner (eds.), Social Capital and the Transition to Democracy, London and New York, Routledge, 2003, P. 215.

13- Kathleen M. Dowley and Brian D. Silver, Social capital, ethnicity and support for democracy in the postcommunist states, In Gabriel Badescu and Eric M. 
Uslaner(eds.), Social Capital and the Transition to Democracy, London and New York, Routledge, 2003, p. 117.

14- Robert Putnam, Bowling Alone. The Collapse and Revival of American Comm unity,( New York, Simon and Schuster, 2000, pp. 22-23.

15- Ashutosh Varshney ,Ethnic Conflict and Civic Life: Hindus and Muslims in India, Yale University Press, New Haven , 2002, pp. 6 -10.

16- Ashutosh Varshney, op. cit, p. 11.

17- Michael Woolcock . The Place of social capital in understanding social and economic outcomes, Canadian Journal of Policy Research, vol.2,no. 1, Spring, 2001, p. 12.

18- Meindert Fennema and Jean Tillie, Political Participation and Political Trust in a Multicultural Democracy: Civic communities and ethnic networks in Amsterdam, Journal of Ethnic and Migration Studies, Vol. 25, No. 4, 1999, pp. 723725 .

19- Meindert Fennema and Jean Tillie, Social Capital in Multicultural Societies, in Dario Castiglione et al. (eds.) ,Handbook of Social Capital, Oxford, Oxford University Press Inc., 2008, pp. 360-365.

20- Pamela Paxton, Social Capital and Democracy: An Interdependent Relationship, op.cit., p.272.

21- Ibed.p.259.

22- Mustafa Emirbayer and Jeff Goodwin, Network Analysis, Culture, and the Problem of Agency, American Journal of Sociology, Vol. 99, No. 6, May, 1994, p. 1417.

23- David Easton, A systems analysis of political life, Chicago, University of Chicago Press, 1979. p.167.

24- Nancy L. Rosenblum, Membership and Morals: The Personal Uses of Pluralism in America, Princeton, Princeton University Press, 1998. p. 329.

25- Avigail Eisenberg and Jeff Spinner-Halev (eds.), Minorities within Minorities: Equality, Rights and Diversity, Cambridge, Cambridge University Press, 2005. p. 204.

26- Michael D. Ward and Kristian S. Gleditsch, Democratizing for Peace, American Political Science Review,Vol. 92, No. 1, March,1998, pp. 53-56. 
27- Yossi Shain and Juan J. Linz . Between States: Interim Governments and Democratic Transitions. Cambridge, Cambridge University Press,1995, p.143.

28- Ronald A.Francisco, The Relationship between Coercion and Protest: An Empirical Evaluation in Three Coercive States, Journal of Conflict Resolution, Vol. 39, No. 2, June, 1995, p. 263.

29- Ted Robert Gurr, Why Minorities Rebel: A Global Analysis of Communal Mobilizationa and Conflict since 1945, International Political Science Review, Vol. 14, No. 2, Apr., 1993, p.163.

30- Jose G. Montalvo and Marta Reynal-Querol,: Ethnic Polarization, Potential Conflict, and Civil Wars, American Economic Review, Vol. 95, No. 3, june, 2005, pp. 796-816.

31- Charles Tilly, Democracy, Cambridge, Cambridge University Press, 2007, p. 109.

32- Monty G. Marshall, Ted Robert Gurr, and Barbara Harff , Political Instability Task Force Problem Set: Internal Wars and Failures of Governance, 1955- 2008, Center for Global Policy, George Mason University, 2009. http://globalpolicy.gmu.edu/pitf/pitfcode.htm (accessed November 3, 2016).

33- Christian Houle, Inequality and Democracy. Why Inequality Harms Consolidation but Does Not Affect Democratization, World Politics, Vol. 61, No. 4, October, 2009, pp. 599-600.

34- Richard Bellamy, Rethinking Liberalism, London and New York, Pinter, 2000, pp.187-201.

35- Will Kymlicka, Multicultural Citizenship: A Liberal Theory of Minority Rights, Oxford, Oxford University Press, 1995, pp.27-78. 


\section{DIVERSITY AND CIVIL PEACE IN THE FRAMEWORKS OF DEMOCRACY/NETWORKS AND INSTITUTIONS}

\section{Muntasser Majeed}

The current research is concerned with studying the values, the producing ties, the standards and reinforced indicators for the state of homogeneity and cohesion at the level of groups and the actors, so as to build and create the capacity to pursue collective aims through mutual cooperation, gathering of resources, and reducing costs, through networks, and rules of conduct, the included trust along the social links (institutionalized or semi-institutionalized). 
ITY 